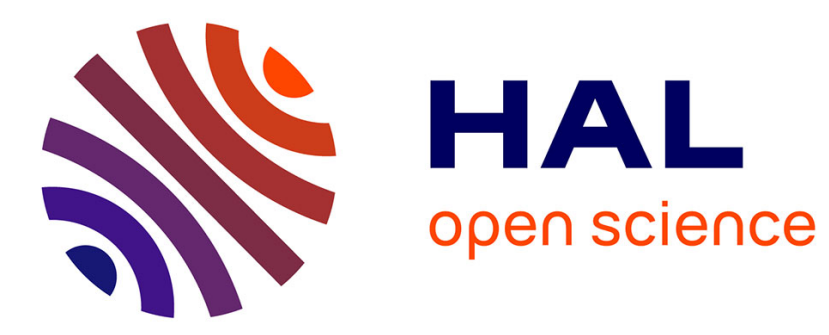

\title{
Flow reactors integrated with in-line monitoring using benchtop NMR spectroscopy
}

\author{
Patrick Giraudeau, Francois-Xavier Felpin
}

\section{To cite this version:}

Patrick Giraudeau, Francois-Xavier Felpin. Flow reactors integrated with in-line monitoring using benchtop NMR spectroscopy. Reaction Chemistry \& Engineering, 2018, 3 (4), pp.399-413. $10.1039 / \mathrm{c} 8 \mathrm{re} 00083 \mathrm{~b}$. hal-02140934

\section{HAL Id: hal-02140934 \\ https://hal.science/hal-02140934}

Submitted on 17 Sep 2021

HAL is a multi-disciplinary open access archive for the deposit and dissemination of scientific research documents, whether they are published or not. The documents may come from teaching and research institutions in France or abroad, or from public or private research centers.
L'archive ouverte pluridisciplinaire HAL, est destinée au dépôt et à la diffusion de documents scientifiques de niveau recherche, publiés ou non, émanant des établissements d'enseignement et de recherche français ou étrangers, des laboratoires publics ou privés. 


\title{
Flow reactors integrated with in-line monitoring using benchtop NMR spectroscopy
}

\author{
Patrick Giraudeau ${ }^{\mathrm{a}, \mathrm{b}}$ and François-Xavier Felpin*a,b
}

\begin{abstract}
${ }^{a}$ Université de Nantes, UFR des Sciences et des Techniques, CNRS UMR 6230, CEISAM, 2 rue de la Houssinière, 44322 Nantes Cedex 3, France

${ }^{\mathrm{b}}$ Institut Universitaire de France, 1 rue Descartes, 75231 Paris Cedex 05, France

* Corresponding author. Tel.: +33-025-112-5422; e-mail: fx.felpin@univ-nantes.fr; ORCID: $\underline{0000-0002-8851-246 \mathrm{X}}$
\end{abstract}

\section{Photograph and biography}

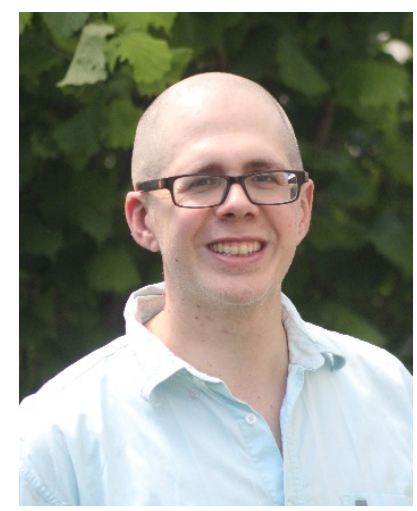

Prof. Patrick Giraudeau is a professor of chemistry at the University of Nantes, France. He obtained his $\mathrm{PhD}$ in 2008, followed by a post-doctoral position at the Weizmann Institute (Israel). His main research focus is the development of quantitative NMR at high and low magnetic field, applied to a variety of fields, from metabolomics and isotopomics to the real time monitoring of (bio)chemical processes. Patrick Giraudeau is a fellow of the Institut Universitaire de France, the vice-president of the French-speaking Metabolomics and Fluxomics Network, a committee member of the Ampere Society, and an associate editor of Magnetic Resonance in Chemistry. 


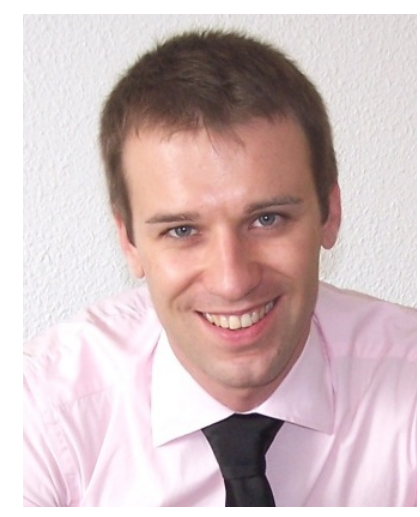

François-Xavier Felpin was born in France in 1977. After earning his Ph.D. at the University of Nantes (France) in 2003, he pursued postdoctoral studies at The Ohio State University (USA). In 2004 he joined the University of Bordeaux as an Assistant Professor and he received his habilitation in 2009. In fall 2011 he moved to the University of Nantes where he was promoted full Professor. Prof. Felpin is a junior member of the Institut Universitaire de France. His research interests include heterogeneous and homogeneous catalysis, new technologies as well as material chemistry.

\begin{abstract}
The monitoring on the fly of chemical reactions conducted in flow through the use of benchtop NMR spectroscopy is an emerging field of research allowing tremendous perspectives. In-line benchtop NMR enables obtaining diversified structural and quantitative data on the chemical composition and determining reaction conversions, kinetics and mechanisms. This review provides an overview of the state-of-the-art of flow reactors integrating in-line monitoring with benchtop NMR spectrometers. A brief discussion on the main characteristics of benchtop NMR and the recent technological developments associated with, are provided in the opening section.
\end{abstract}

\title{
Introduction
}

Continuous flow chemistry has been one of the most influential technologies of the last decade in creative processes impacting organic synthesis. ${ }^{1-9}$ Micromixing, efficient heat transfer in tubular reactors having a high surface-to-volume ratio and enhanced safety due to the small size of reactors are some of the most salient benefits of continuous flow chemistry compared to traditional batch processes. ${ }^{10-13}$ As a result, flow approaches in synthetic chemistry rapidly thrives in academic and industrial laboratories ${ }^{14-18}$ and affords considerable opportunities to develop novel transformations and access new reactivities under unusual experimental 
conditions. ${ }^{19-24}$ Both, deep mechanistic understanding and optimization of complex synthetic transformations conducted either in flow or in batch modes, require the use of suitable analytical technologies. While in the traditional approach a combination of several off-line analyses are frequently privileged, flow reactors are particularly suitable for the monitoring of chemical reactions on the fly through the integration of in-line analytical tools. ${ }^{25,26}$ The acquisition of analytical data in real time through in-line monitoring allows fast and efficient screening of the reaction composition for the visualization of hazardous or air-sensitive intermediates and offers the possibility of adapting one or more reaction parameters.

In the ideal situation, the in-line characterization must be fast (quasi real time), sensitive to detect trace-amount of intermediates and non-invasive to prevent any modification or destruction of the analyzed sample. In the recent years, several in-line characterization techniques have been integrated to flow reactors and they can be regarded as chromatographic spectrometric and spectroscopic detection methods; each analytical tool has its own strengths and weaknesses. Chromatographic methods such as liquid chromatography (LC) and gas chromatography (GC) are often privileged due to the facile separation of products but they suffer from a weak time efficiency and do not allow structural identification. ${ }^{27-29}$ Mass spectrometry (MS) used on its $\mathrm{own}^{30-32}$ or in association with chromatographic methods (LCMS and GC-MS) ${ }^{33,34}$ gives valuable information but with limited structural information. Infrared spectroscopy (IR) allows the identification of structural elements in quasi-real time but the analysis is often plagued by overlapping issues. ${ }^{35-39}$ High-field nuclear magnetic resonance (HF-NMR) is certainly the most powerful and sophisticated spectroscopic technique at the disposal of organic chemists but its integration to flow reactors is complicated by the cost and the size of NMR machines which are, in addition, rarely installed close to a fume hood. ${ }^{40-43}$ Benchtop NMR equipped with a permanent magnet recently appeared as a powerful alternative to HF-NMR as it does not require cryogenic liquid and can be installed under a fume hood. This reviews aims at timely describing the early examples of flow reactors integrated with benchtop NMR as in-line analytical tool, providing the main strengths and weaknesses of this emerging technology. As introductory part, the main characteristics of benchtop NMR and the recent technological developments will also be thoroughly discussed. It must be mentioned that the use of in-line vs. on-line is a subject of debate leading to a certain degree of confusion. Therefore, we decided to use "in-line NMR" in this review for any experimental setup integrating into the flow reactor a NMR spectrometer directly into the stream without interruption of the flow. 


\section{Benchtop NMR}

NMR spectroscopy has been used for a long time to monitor chemical reactions in-line, thanks to its ability to provide both unambiguous structural information and accurate quantitative data. High-field (HF) NMR has been the tool of choice for most studies, either thanks to dedicated flow probes ${ }^{44}$ or more recently using flow tubes that can be adapted to a routine NMR hardware configuration. ${ }^{45}$ Although benefiting from a high sensitivity and resolution, HF NMR spectrometers are barely compatible with flow chemistry on a routine basis, since these heavy and expensive equipment are generally located in dedicated laboratories and operated by specialized staff. Low-field (LF) NMR, based on small permanent magnets operating at a low magnetic field, has the potential to circumvent many of these drawbacks thanks to a reduced size that makes it compatible with a synthetic chemistry environment such as a fume hood.

LF NMR has been limited for decades to the field of relaxometry, with permanent magnets operating at low magnetic field (typically $0.5 \mathrm{~T}$ ) whose homogeneity was not sufficient to provide NMR spectra with a decent resolution. In relaxometry experiments, the relevant information consists in a distribution of relaxation times obtained by fitting the Free Induction Decay (FID). While this approach was successfully applied to monitor chemical processes in real time, ${ }^{46,47}$ it is limited to certain classes of reactions where the reactants and products are characterized by significantly different relaxation behaviors.

More recently (in the 2010s), a new generation of low-field NMR spectrometers has emerged as a very promising alternative. These so-called "benchtop" spectrometers also rely on permanent magnets, but the homogeneity of the latter has become sufficient to record conventional NMR spectra with a reasonable resolution. ${ }^{48}$ Since 2015 , benchtop spectrometers have opened new markets for NMR, making it accessible to demanding environments such as production sites or synthetic chemistry labs. Benchtop NMR spectrometers, which have become commercially available from several companies, benefit from a reasonable cost $(50-100 \mathrm{k} €$ versus $500 \mathrm{k} €$ to several millions for HF spectrometers) and from almost negligible working costs. They do not require cryogenic fluids since they are based on rare earth permanent magnets. The currently available equipment operate at magnetic fields between 1 and $2 \mathrm{~T}$, corresponding to a ${ }^{1} \mathrm{H}$ Larmor frequency of $c a .40$ to $80 \mathrm{MHz}$.

These new instruments have paved the way to applications of NMR in fields like reaction monitoring, ${ }^{49}$ process control ${ }^{50}$ but also in teaching labs, ${ }^{51}$ where the access to HF NMR was previously limited. In addition, the limited volume and low cost of benchtop NMR spectrometers make them ideal candidates as an in-line analytical technique (Fig. 1a). While 
they can analyze samples in regular NMR tubes, they also come with a flow system consisting of a flow-cell and a pump which are designed for in-line monitoring. Another advantage is that benchtop spectrometers can operate without deuterated solvents, thanks to an integrated fieldfrequency lock system. The obvious benefits are the reduced cost of the monitoring and the suppression of potential isotopic effects that might occur in deuterated solvents. Finally, a broad range of nuclei can be detected by benchtop NMR spectroscopy, although almost each nucleus requires a different hardware (contrary to HF NMR, there is currently no tunable broadband probe for benchtop NMR). Most common system can detect ${ }^{1} \mathrm{H},{ }^{19} \mathrm{~F}$, and sometimes a third nuclei depending on the commercial model -typically ${ }^{13} \mathrm{C}$ or ${ }^{31} \mathrm{P}$.

Obviously, decreasing the magnetic field comes at a price. The two main limitations of benchtop NMR spectroscopy are sensitivity and resolution. The NMR sensitivity -which scales with $\mathrm{B}_{0}^{3 / 2}$ where $\mathrm{B}_{0}$ is the static magnetic field- is significantly reduced, which means that benchtop spectrometers are limited to the detection of relatively concentrated molecules, typically several tens of $\mathrm{mM}$ (or less for the most recent $80 \mathrm{MHz}$ spectrometers). This is compensated by very sharp lines (less than $1 \mathrm{~Hz}$ ) thanks to a high magnet homogeneity, but the resolution (i.e., the ability to distinguish nearby peaks) is limited by the small frequency range, proportional to $\mathrm{B}_{0}$. For instance, $10 \mathrm{ppm}$ correspond to only $430 \mathrm{~Hz}$ on a $43 \mathrm{MHz}$ spectrometer, which leads to ubiquitous overlap between multiplets, the coupling constants $J$ being independent on the field. As illustrated in Fig. 1b, strong peak overlaps occur on ${ }^{1} \mathrm{H}$ spectra, even for a simple small molecule such as ibuprofen 1. In addition to these sensitivity and resolution issues, low-field NMR spectra are characterized by strong second order effects, since the chemical shift difference between coupled spins often becomes comparable to the resonance frequency. This leads to spectral patterns which are significantly distorted compared to their HF counterpart (Fig. 1b-c). A last drawback, inherent to the technological design of the permanent magnet, is their sensitivity to temperature variations outside the magnet. These rareearth magnets are optimally stable for a room temperature between 20 and $30^{\circ} \mathrm{C}$, and variations outside of this range result in magnet instability. 

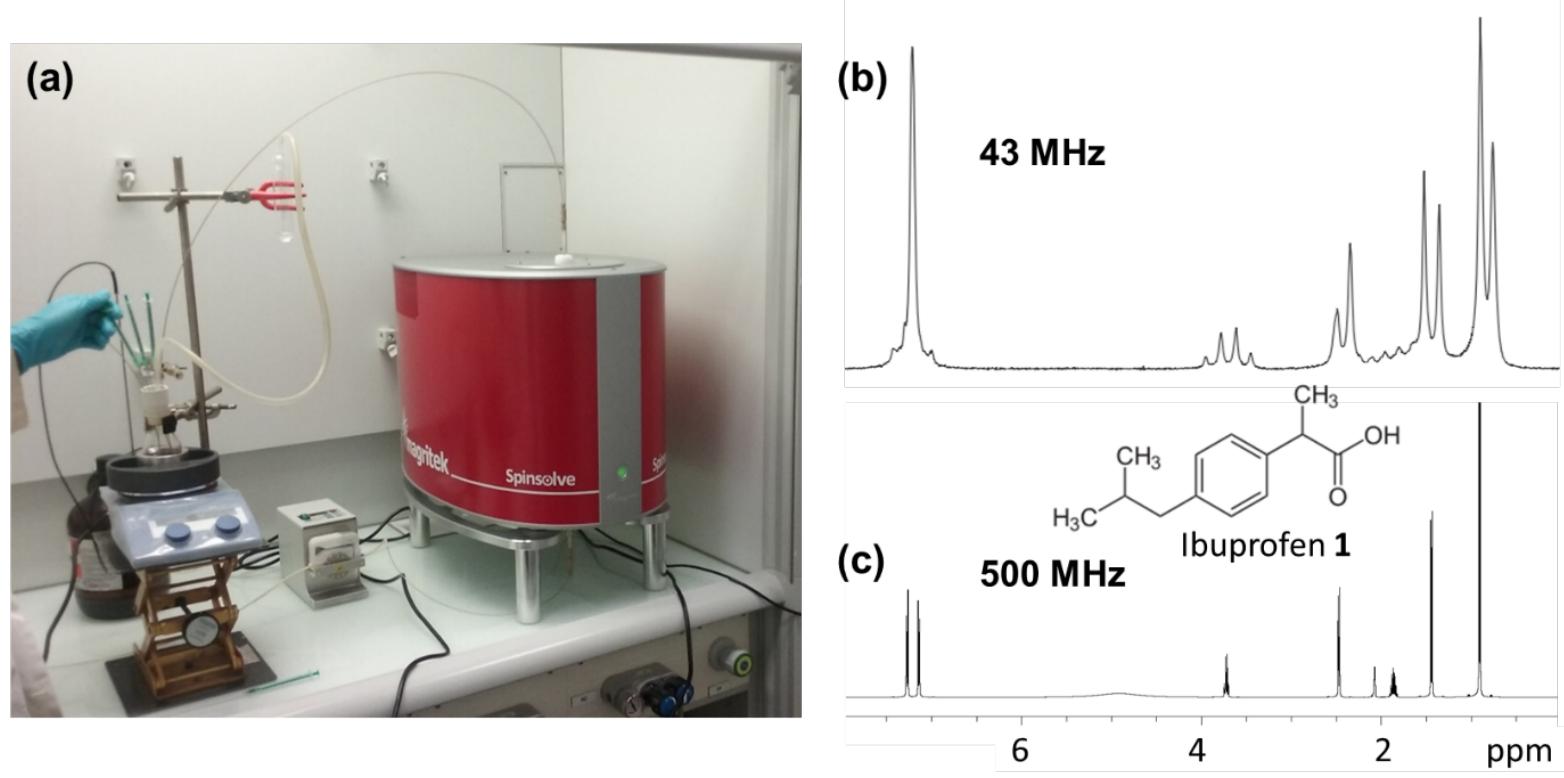

Fig. 1 (a) $43 \mathrm{MHz}$ benchtop NMR spectrometer installed under a fume hood in in-line monitoring conditions at the CEISAM research institute, University of Nantes, France. (b) ${ }^{1} \mathrm{H}$ NMR spectrum of ibuprofen 1 in acetone- $d_{6}$ recorded at $43 \mathrm{MHz}$ on a benchtop spectrometer. (c) ${ }^{1} \mathrm{H}$ NMR spectrum of the same sample recorded at $500 \mathrm{MHz}$ on a high-field NMR spectrometer.

The abovementioned limitations highlight the need for methodological developments capable of improving the performance of benchtop NMR spectrometers. Current hardware developments (mostly performed by manufacturers) aim at increasing the available magnetic field to improve the sensitivity and resolution, while maintaining a strong magnet homogeneity to ensure sharp NMR peaks. In parallel, NMR research groups are developing advanced NMR methods to boost the performance of benchtop NMR for applications in chemistry. Pulse programming has become possible on benchtop settings, and the implementation of modern NMR pulse sequences - such as those developed at HF- has been boosted by the recent implementation of gradient coils in commercial spectrometers. Gradient coils -present on all modern HF NMR probes- induce a spatial variation of the resonance frequency which opens up numerous possibilities for NMR pulse sequence designers, from the selection of a signal of interest to modern solvent suppression techniques or to spatially-encoded experiments. Recent pulse sequence developments at low-field are highlighted in Fig. 2. They include the implementation of advanced flow-compatible solvent-suppression pulse sequences (Fig. 2a-b), which are indispensable to reduce the strong signal of non-deuterated solvents and detect the signals of interest in a reacting mixture. ${ }^{52}$ An application example of this approach to flow 
chemistry is described in the next section. Another recent methodological advance is the development of ultrafast (UF) 2D NMR methods at low field. UF 2D NMR can record 2D NMR correlation spectra in a fraction of a second, ${ }^{53}$ and has been developed for 15 years at $\mathrm{HF},{ }^{54}$ leading to major applications in various areas of chemistry, from reaction monitoring to highthroughput metabolomics. ${ }^{55}$ We have recently developed UF 2D NMR on a benchtop spectrometer (Fig. 2 c-d), and a first application to real-time reaction monitoring has been reported, ${ }^{56}$ although this approach remains limited by sensitivity considerations.
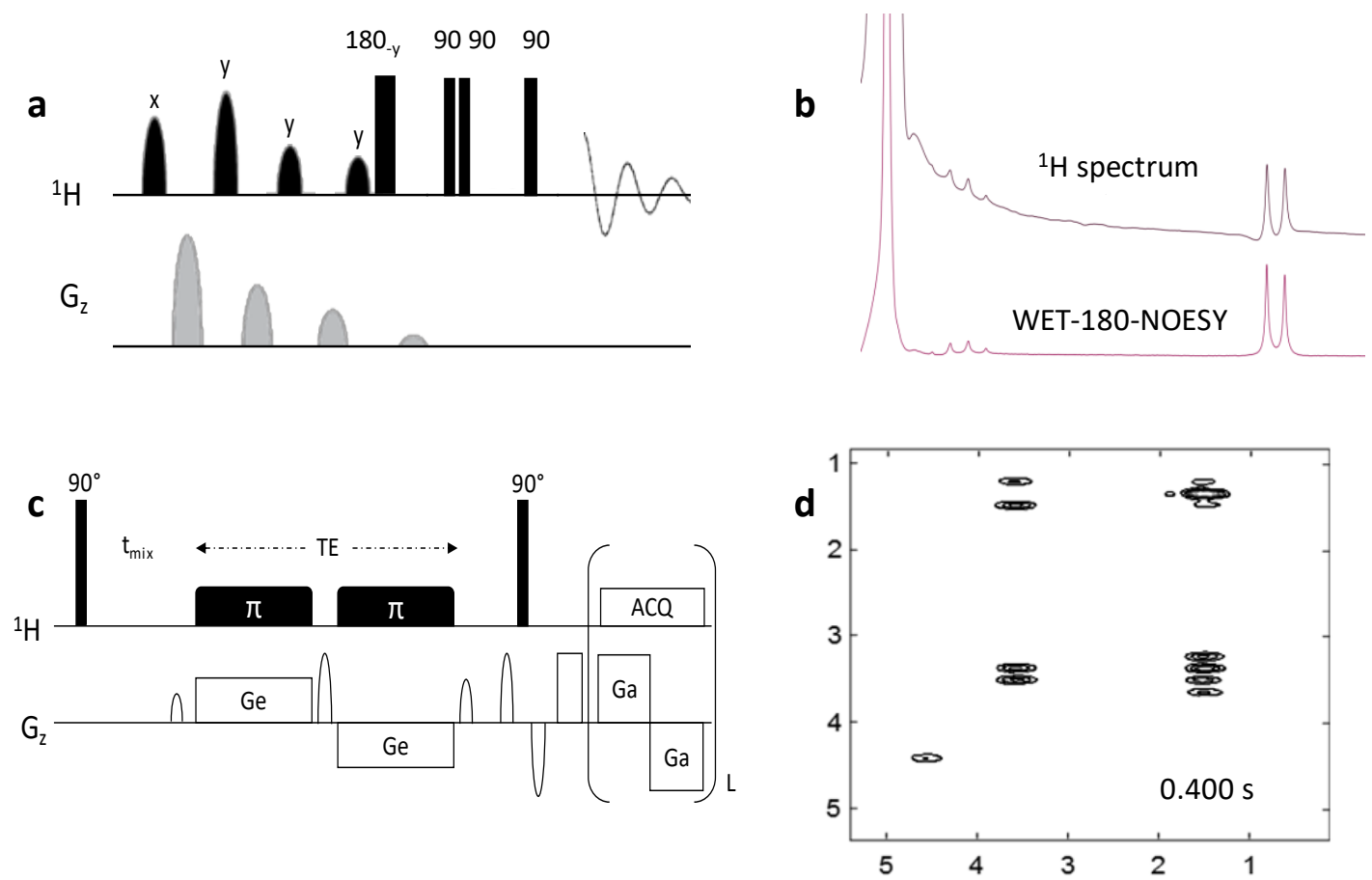

Fig. 2 Advanced gradient-based NMR methods implemented on a benchtop NMR spectrometer. (a) WET-180-NOESY solvent suppression pulse sequence, and (b) associated 1D NMR spectra obtained on a sample of lactate in $\mathrm{H}_{2} \mathrm{O}$, without solvent suppression (top) and with a WET-180-NOESY pulse sequence (bottom). Spectra reproduced from ref. 51 with permission from John Wiley \& Sons. (b) Ultrafast 2D COSY pulse sequence and (c) associated spectrum recorded in a single scan on a sample of ethanol. Spectrum reproduced from ref. 56 with permission from The Royal Society of Chemistry.

A last peculiarity to take into account - not specific to benchtop NMR- is the impact of continuous flow on the sensitivity of the NMR detection, which translates into different effects. ${ }^{52}$ First, the flow leads to a continuous refreshment of the spins in the sensitive coil volume by freshly polarized spins. This "inflow effect" can help shortening the repetition time 
between successive NMR scans, since it decreases the apparent longitudinal relaxation time. However, the inflow effect enhances the sensitivity per unit time as long as the flow rate is sufficiently low to allow the spins entering the magnet to be polarized before detection. If the flow rate is too high, the sensitivity can dramatically decrease. Second, the continuous flow also generates an "outflow effect" which consists in excited spins leaving the sensitive volume before the end of the acquisition time. This outflow effect reduces the apparent transverse relaxation times, leading to peak broadening. Typically, for small organic molecules, flow rates between 0.5 to $2.0 \mathrm{~mL} / \mathrm{min}$ give rise to the optimum sensitivity per unit time.

\section{In-line monitoring of continuous flow processes with benchtop NMR}

The non-invasive nature of the NMR detection is a salient advantage compared to traditional chromatographic (LC, GC) or spectrometric methods (MS) for the monitoring of highly reactive compounds such as organometallic reagents. This feature was highlighted by Duchateau et al. through the development of a continuous flow process for the preparation of Grignard reagents with an integrated benchtop NMR analysis. ${ }^{57}$ Grignard reagents constitute an extremely popular class of organometallic compounds widely used in both academic and industrial laboratories. The preparation of organomagnesium compounds has been almost unchanged since their discovery in 1900 by Victor Grignard. At both laboratory and industrial scales, Grignard reagents are still mainly produced from solid magnesium (powder of turnings) and alkyl or aryl halides in tank reactors, although efficient procedures have also been developed in flow reactors. ${ }^{36,38,58-62}$

Classical issues associated with the preparation of Grignard reagents are the unreliable reactivity of solid magnesium which highly depends on the hygrometry conditions, the level of surface oxidation and the control of the exothermicity of the reaction. These irreproducibility issues, leading to the formation of an unpredictable amount of Grignard reagents in the tank reactor, justifies the need to quantify the concentration organomagnesium compounds by titration. However, this extra step requires additional a hazardous handling with a potential exposure of this highly sensitive compounds to air and moisture.

The approach reported by Duchateau et al. addressed most of the issues listed above as thermodynamic parameters were precisely controlled in the flow reactor while the in-line analysis facilitated the quantification of Grignard reagents without off-line hazardous handling. The experimental setup, depicted in Fig. 3, consisted in a stainless steel vertical tube $(75 \mathrm{~mL})$ covered by a heating/cooloing jacket and loaded with magnesium powder $(10 \mathrm{~g}, 250 \mu \mathrm{m}$ 
particles). The solution of halide substrates was pumped through the reactor with a HPLC pump at a $5 \mathrm{~mL} / \mathrm{min}$ flow rate. The tube was positioned vertically to keep magnesium particles as a fluidized bed in the solvent flow, preventing the magnesium particles from settling. At the outlet of the reactor, the stream was splitted in order to fill the NMR cell at a $1 \mathrm{~mL} / \mathrm{min}$ flow rate while the remaining stream was directed to the fraction collector at $4 \mathrm{~mL} / \mathrm{min}$. For the continuous monitoring the evolution of the aromatic signals were followed through recording of ${ }^{1} \mathrm{H}$ NMR spectra every 10-15 seconds at $42 \mathrm{MHz}$ (Fig. 3). The in-line analysis provided authors with important information in a short time frame since, for instance, they observed that the synthesis of phenylmagnesium bromide 3 was best carried out at temperature ranging from 40 to $80{ }^{\circ} \mathrm{C}$ while a flow rate $>5 \mathrm{~mL} / \mathrm{min}$ led to an incomplete production of the Grignard reagent. With the same flow setup other Grignard reagents were prepared starting from iodobenzene, cyclopropylbromide, methylchloride, 4-bromo-tert-butylbenzene and 4bromobenzaldehyde dimethylacetal.

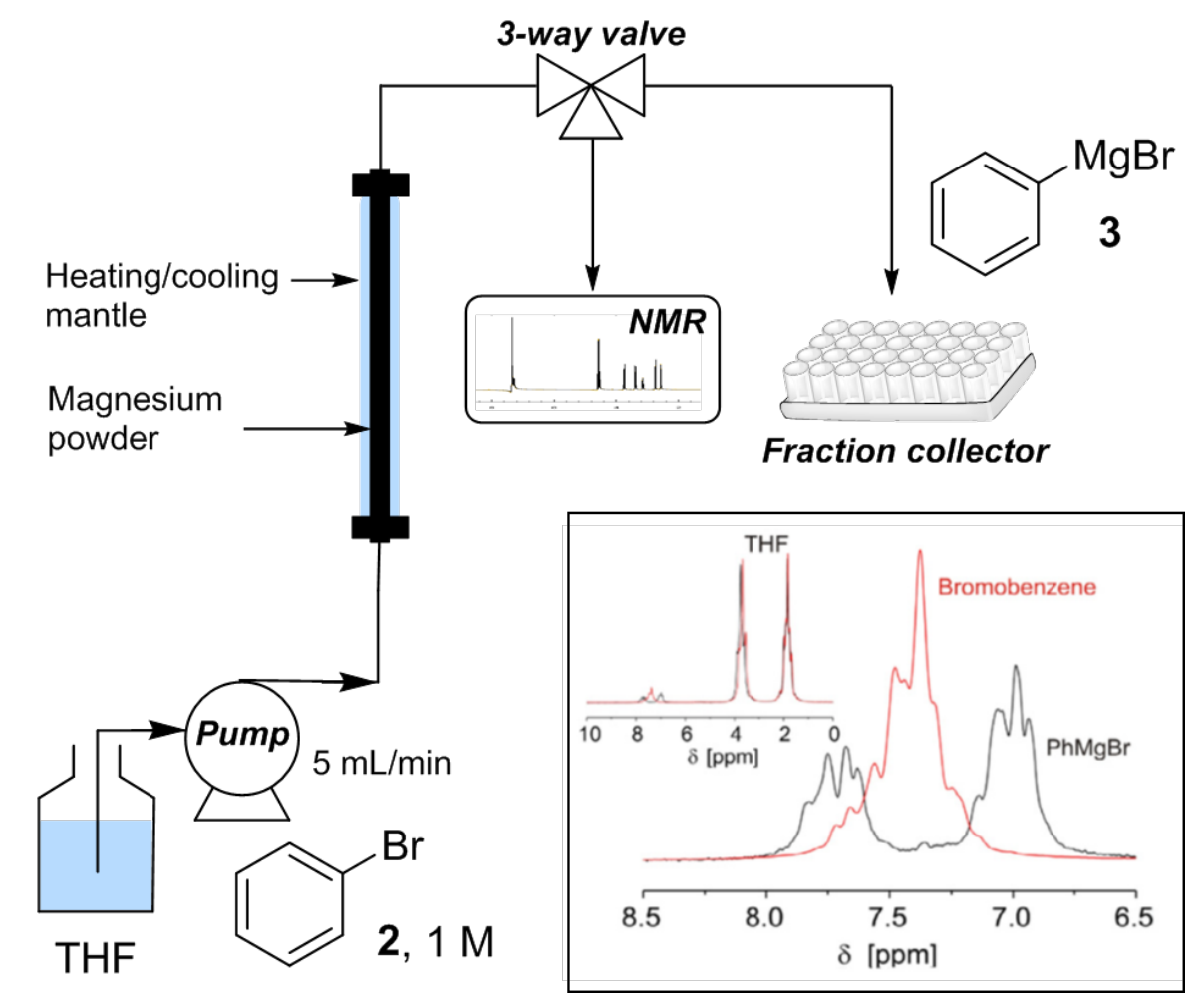

Fig. 3 Flow setup for the preparation of Grignard reagents. In the frame, ${ }^{1} \mathrm{H}$ NMR spectra of bromobenzene 2 ( $1 \mathrm{M}$ in THF) and phenylmagnesium bromide 3 (1 $\mathrm{M}$ in THF) recorded with a benchtop NMR spectrometer at $42 \mathrm{MHz}$. The NMR spectra were reproduced from ref. 57 with permission from Elsevier Ltd. 
The destruction of chemical warfare agents has become a severe concern for security forces since conventional procedure involving the transfer of chemical weapon to highly secured and dedicated sites is not well adapted to modern conflicts. Current conflicts, occurring in the middle-east and in Africa, are exported in occidental countries in the form of terrorist attacks in densely populated area, at the heart of large cities, where the handling of hazardous chemical weapon and explosives for off-site destruction is perilous.

In order to address this concern, Legros and co-workers proposed an original strategy based on an on-board flow device with an integrated in-line benchtop NMR analysis for the oxidative neutralization of mustard compounds. ${ }^{63}$ The proof-of-concept was validated for the neutralization of the mustard-gas simulant 2-chloroethyl ethyl sulfide 4 (CEES). The portable flow device consisted in a two-stream flow reactor connected to a benchtop low-field NMR spectrometer (Fig. 4). Under optimal conditions, a solution of CEES 4 in $\mathrm{MeOH}(0.85 \mathrm{M})$ was pumped at a $0.06 \mathrm{~mL} / \mathrm{min}$ flow rate and met, through a stainless steel T-shaped mixer, a second line containing a solution of hydrogen peroxide-urea $(0.1 \mathrm{M})$ and methane sulfonic acid $(0.2$ $\mathrm{M})$ in $\mathrm{MeOH}$ and pumped at $0.69 \mathrm{~mL} / \mathrm{min}$. The resulting mixture entered in a PFA tubbing (V $=0.85 \mathrm{~mL}$ ) where the oxidation occurred and the crude mixture was directly delivered to the NMR flow cell connected at the outlet of the reactor. The crude composition and the reaction conversion were analyzed in a quasi-real time by recording ${ }^{1} \mathrm{H}$ NMR spectra at $43.62 \mathrm{MHz}$ every 13 seconds.

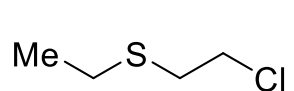

4, $0.85 \mathrm{M}$

$\mathrm{H}_{2} \mathrm{O}_{2}$-urea $0.1 \mathrm{M}$

$\mathrm{MeSO}_{3} \mathrm{H} \quad 0.2 \mathrm{M}$

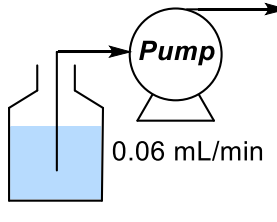

$\mathrm{MeOH}$

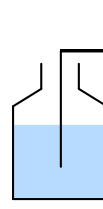

$\mathrm{MeOH}$

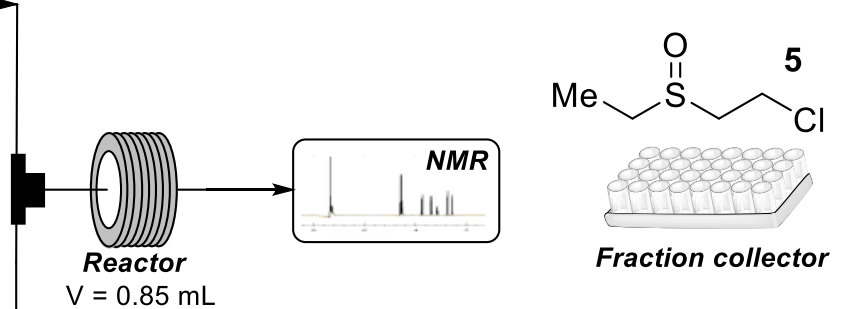

Fig. 4 Flow setup for the oxidation of CEES 4 into CEESO 5.

The oxidation of CEES 4 into the corresponding 2-chloroethyl ethyl sulfoxide 5 (CEESO) was followed over a large range of residence time from $c a$. 17 to 100 seconds (Fig. 5). It was not possible to assess lower residence times, corresponding to flow rates exceeding $3 \mathrm{~mL} / \mathrm{min}$ 
as the well-known outflow effect led to a strong line-broadening due to a reduction of the effective transverse relaxation time (as mentioned in the previous section). The NMR device used by Legros and co-workers featured an external fluorine lock system, allowing to carry out experiment in non-deuterated solvent. As mentioned earlier, using non-deuterated solvents is not without consequence for ${ }^{1} \mathrm{H}$ NMR analyses since the strong solvent signal - usually in excess with respect to the reagents - frequently overlap the resonances of interest, ultimately precluding any assessment of conversion or yield. In their preliminary studies, Legros et al. were faced with this issue since the strong peak of $\mathrm{MeOH}$ at $3.3 \mathrm{ppm}$ overlapped the resonances of CEES 4 and CEESO 5 at 2.5 and 3.8 ppm, respectively. This solvent signal was efficiently saturated thanks to an advanced solvent suppression method, WET-180-NOESY, combined with a continuous wave presaturation to suppress another strong signal from exchangeable protons at $5.37 \mathrm{ppm}$. This highlights the need for advanced solvent suppression methods to monitor reactions in flow at low field. In addition, the experimenter has to subtract the contribution from a ${ }^{13} \mathrm{C}$ satellite peak from the solvent by a deconvolution approach.

To assess the viability of such equipment in real situation, a scale-up experiment was conducted with the neutralization of $25 \mathrm{~g}$ of the CEES 4 mustard-gas simulant within 46 minutes. 

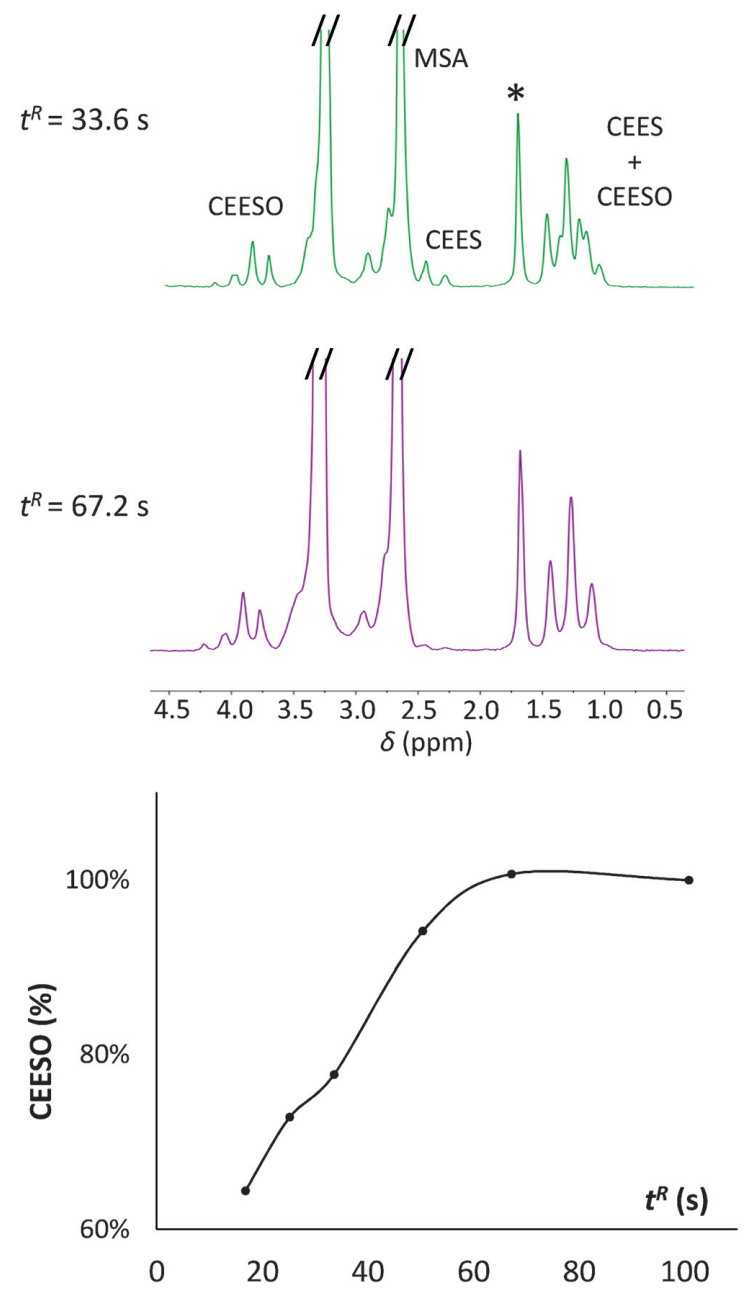

Fig. 5 Neutralization of CEES 4 monitored by an in-line NMR system. Top and middle: Two NMR spectra recorded at different residence times. Note that the peak with a * corresponds to a 13C satellite line from the residual solvent signal at $3.3 \mathrm{ppm}$. Bottom: Percentage of CEESO 5 as a function of the residence time. Reproduced from ref. 63 with permission from John Wiley \& Sons.

When ${ }^{1} \mathrm{H}$ NMR spectra show inextricable overlapped signal, ${ }^{19} \mathrm{~F}$ NMR experiments are interesting alternatives since the large range of chemical shifts from -300 to $100 \mathrm{ppm}$ limits potential signal overlapping issues. ${ }^{19} \mathrm{~F}$ NMR measurements are fast and the ${ }^{19} \mathrm{~F}$ nucleus is $100 \%$ naturally abundant, providing a sensitivity comparable to the ${ }^{1} \mathrm{H}$ nucleus. The obvious benefits of ${ }^{19} \mathrm{~F}$ NMR experiments were recognized by Rehm et al. who developed a continuous flow synthesis of fluorine-containing compounds with an integrated low-field ${ }^{19} \mathrm{~F}$ NMR analysis. ${ }^{64}$ The authors used a benchtop NMR spectrometer working at $55.17 \mathrm{MHz}$ for the ${ }^{19} \mathrm{~F}$ nucleus. The chemical reactions investigated in this study, i.e., Krapcho decarboxylation, RuppertPrakash perfluoroalkylation and visible-light $\mathrm{C}-\mathrm{H}$ arylation, were carried out in conventional non-deuterated solvents and the NMR sequences were locked and shimmed on the ${ }^{1} \mathrm{H}$ signal of 
the solvent. The commercially available benchtop spectrometer used in this study was initially not designed to carry out analyses in flow as it required the use of standard glass NMR tubes. Therefore, an NMR flow cell was designed to connect the NMR spectrometer at the outlet of the reactor for an in-line analysis. A complex lab plant was designed to be compatible with various chemical reactions, including photocatalyzed processes, and unsolicited functionalities of the flow device were easily by-passed through the use of 3-way valves (Fig. 6). All components of the integrated lab plant, including the NMR spectrometer, were fully computercontrolled through a graphical interface created with LabView which automatically recovered the spectral data for further automated data processing.

For instance, the visible-light-initiated eosin Y photocatalyzed arylation of furan 6 with 3fluoromethylbenzene diazonium tetrafluoroborate 7 the lab plant featured two-streams. In the first inlet a solution of the diazonium salt 7 in DMSO (0.4 M) was mixed in a PEEK T-shaped static micromixer with a solution of eosin Y $(1 \mathrm{~mol} \%)$ and furan $6(2 \mathrm{M})$ in DMSO introduced through a second line. The merged streams entered in a capillary photoreactor illuminated with a green LED at $c a .525 \mathrm{~nm}$. The nitrogen gas released during the reaction was evacuated through a gas-liquid splitter placed at the outlet of the photoreactor. The conversion was easily followed by the in-line NMR spectrometer with the evolution of two singlet resonances of the trifluoromethyl group at -66.60 and -66.06 pm for the diazonium salt and coupling product, respectively. The tetrafluoroborate counterion, displaying a singlet resonance at $152.6 \mathrm{ppm}$, was conveniently used as internal standard. The authors observed a complete conversion at flow rates ranging from 0.5 to $1 \mathrm{~mL} / \mathrm{min}$. However, the volume of the capillary flow reactor being not reported, it is not possible to comment on the residence time and productivity efficiency. 


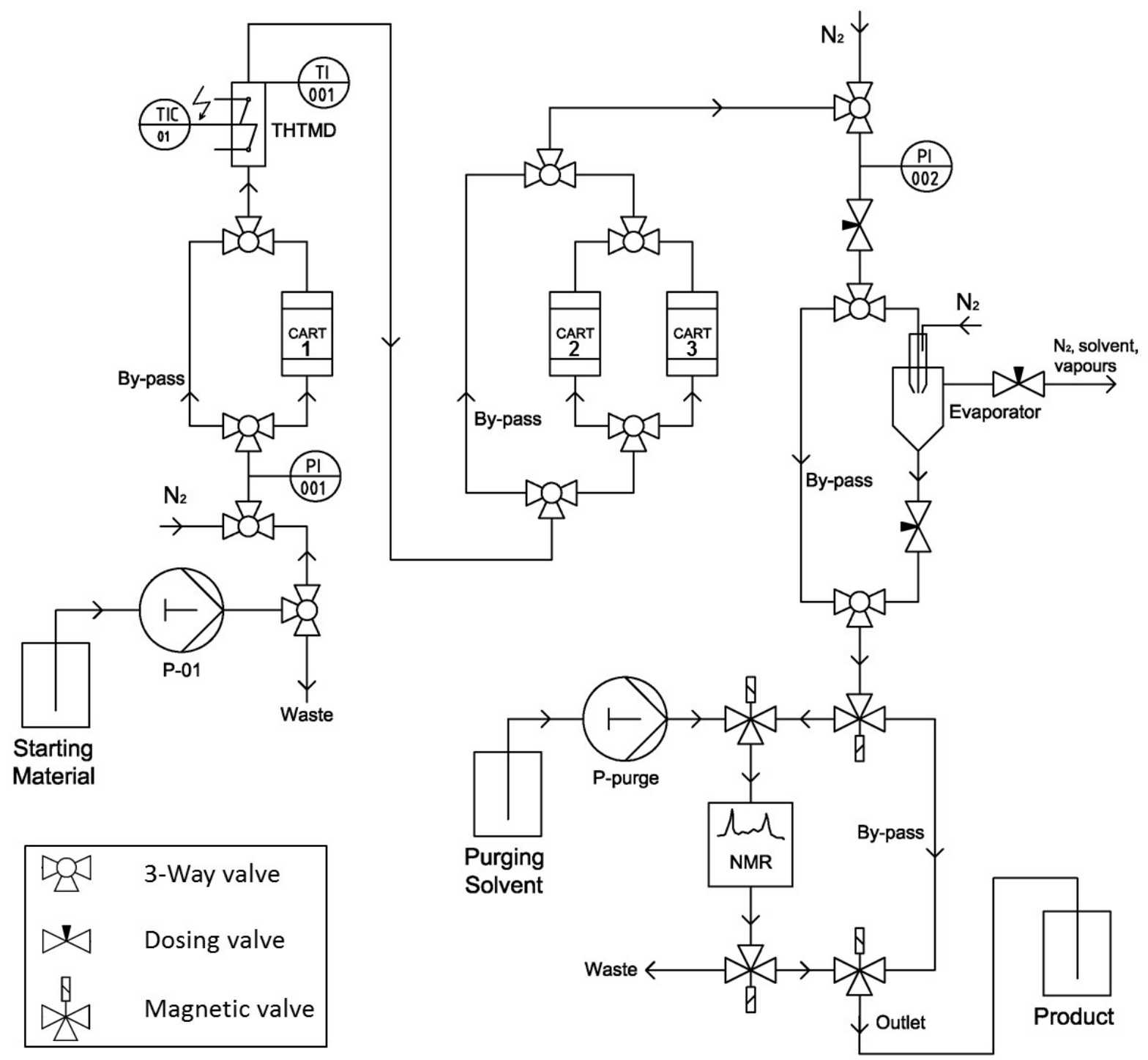

Fig. 6. Representation of the lab plant with integrated benchtop NMR analysis. Reproduced from ref. 64 with permission from The Royal Chemical Society.

Obviously, the use of ${ }^{19} \mathrm{~F}$ NMR experiments is limited to the monitoring of compounds bearing fluorine atoms and another strategy is required when peak identification and integration of fluorine-free reaction mixtures are constrained by the resonances of protonated solvents. The use of deuterated solvents as reaction media addresses this issue but this strategy is prevented by the high associated cost. The group of Ley proposed an ingenious strategy consisting in switching the protonated media used in the continuous flow process by a deuterated solvent, using a solvent switching system placed at the outlet of the reactor. This enabling technology allows to carry out uninterrupted reaction-to-analysis sequences and prevents the use of expensive deuterated solvents as reaction media. The operating principle of the solvent switching system, constructed from commercially available parts, is based on the exposure of 
a high surface spray of solvent to a stream of air as desolvating gas. ${ }^{65}$ Such a prototype was integrated in a continuous flow reactor equipped with an in-line benchtop NMR spectrometer for the hypervalent iodine(III)-mediated cyclopropanation of 4-tert-butylstyrene 8 with malononitrile 9 to 1,1-dicyanocyclopropane 10. ${ }^{66}$ The solvent switching system was employed to switch from $\mathrm{CH}_{2} \mathrm{Cl}_{2}$, used as the reaction solvent, to $\mathrm{CDCl}_{3}$, used as media for NMR analysis. The switch was required to follow the reaction progress by ${ }^{1} \mathrm{H}$ NMR as the broad singlet of $\mathrm{CH}_{2} \mathrm{Cl}_{2}$ at $\mathrm{ca} .5 .30 \mathrm{ppm}$ overlapped the resonances from vinylic protons of $\mathbf{8}$. In the optimized flow setup, consisting of two streams, 4-tert-butylstyrene $8(0.25 \mathrm{M})$ and malononitrile 9 (0.3 $\mathrm{M})$ in $\mathrm{CH}_{2} \mathrm{Cl}_{2}$ were loaded into a first $2 \mathrm{~mL}$ loop while $\mathrm{PhI}(\mathrm{OAc})_{2}(0.55 \mathrm{M})$ was charged in a second $2 \mathrm{~mL}$ loop (Fig. 7). Each way were pumped at $0.05 \mathrm{~mL} / \mathrm{min}$ and flowed simultaneously through an Omnifit-glass column $(4.5 \mathrm{~mL})$ loaded with $\mathrm{K}_{2} \mathrm{CO}_{3}$ and heated at $60{ }^{\circ} \mathrm{C}$. The line was pressurized at $40 \mathrm{psi}$ with a back pressure regulator to prevent the volatilization of $\mathrm{CH}_{2} \mathrm{Cl}_{2}$. The reaction stream output was connected to the solvent switch system and the crude mixture diluted in $\mathrm{CDCl}_{3}$ was delivered to the benchtop NMR device. Through the in-line monitoring, authors extracted the integration values of selected resonances to plot the relative integration intensity as a function of time and determine the steady-state profile.

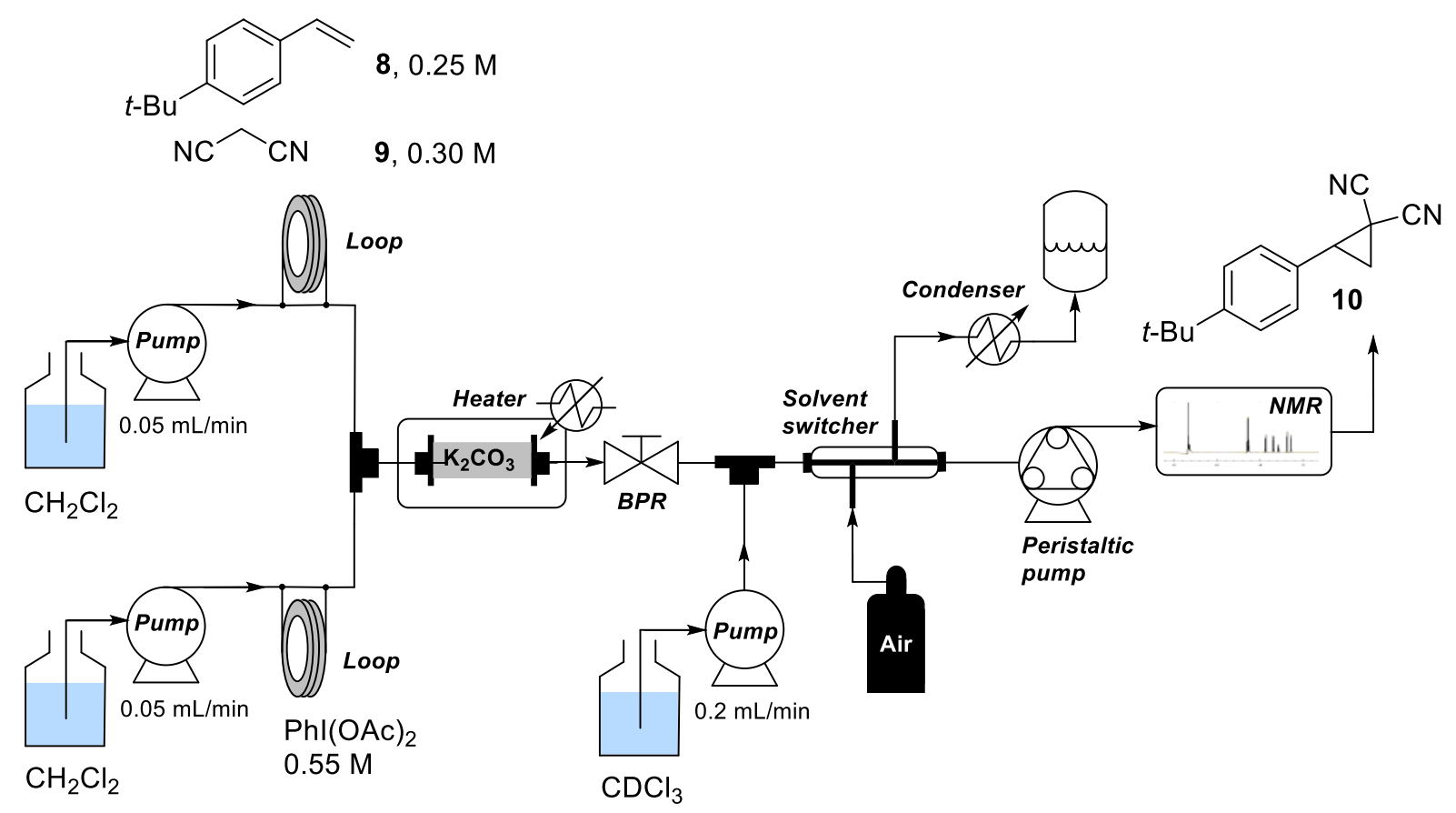

Fig. 7 Flow setup for the cyclopropanation of 4-tert-butylstyrene 8 with malononitrile 9.

While issues associated with signal overlaps resulting from the use of non-deuterated reaction solvent can be efficiently addressed with the use of a solvent switcher, another strategy 
is required when the overlapping concerns resonances from the reagents and products. This problem is particularly significant at low field where the spectral windows is reduced. A significant spectral resolution enhancement is provided by 2-dimensional (2D) NMR spectroscopy where resonances are spread over a 2D map. The use of $2 \mathrm{D}$ experiments at low field being particularly relevant, several homo- and heteronuclear 2D pulse-sequences, including ultrafast methodologies, have been recently implemented on benchtop spectrometers. $^{56,67}$

In this framework, the group of Ley designed a flow reactor allowing reaction monitoring with 2D pulse-sequences implemented on a benchtop NMR spectrometer. ${ }^{66}$ This flow device was set for the continuous flow cyclopropanation of 4-tert-butylstyrene 8 with ethylnitroacetate 11 to cyclopropane 12 under $\mathrm{Rh}_{2}(\mathrm{esp})_{2}$ catalysis in $\mathrm{CH}_{2} \mathrm{Cl}_{2}$. In the two stream flow setup, the first loop was loaded with 4-tert-butylstyrene $8(0.50 \mathrm{M})$ and ethylnitroacetate $11(0.55 \mathrm{M})$ in $\mathrm{CH}_{2} \mathrm{Cl}_{2}$ while the second one was charged with $\mathrm{PhI}(\mathrm{OAc})_{2}(0.55 \mathrm{M})$ and $\mathrm{Rh}_{2}(\mathrm{esp})_{2}(0.5 \mathrm{~mol} \%)$ in $\mathrm{CH}_{2} \mathrm{Cl}_{2}$ (Fig. 8). Both lines were pumped at $0.03 \mathrm{~mL} / \mathrm{min}$ and delivered the reaction mixture in a PTFE coil reactor $(1.8 \mathrm{~mL})$ heated at $50{ }^{\circ} \mathrm{C}$ and pressurized at 40 psi. Upon switching $\mathrm{CH}_{2} \mathrm{Cl}_{2}$ for $\mathrm{CDCl}_{3}$, the crude mixture was analyzed by in-line NMR spectroscopy using a custom-made loop sequence of $1 \mathrm{D}^{1} \mathrm{H}$ NMR and 2D COSY, recorded every 13 minutes over 3 loops.

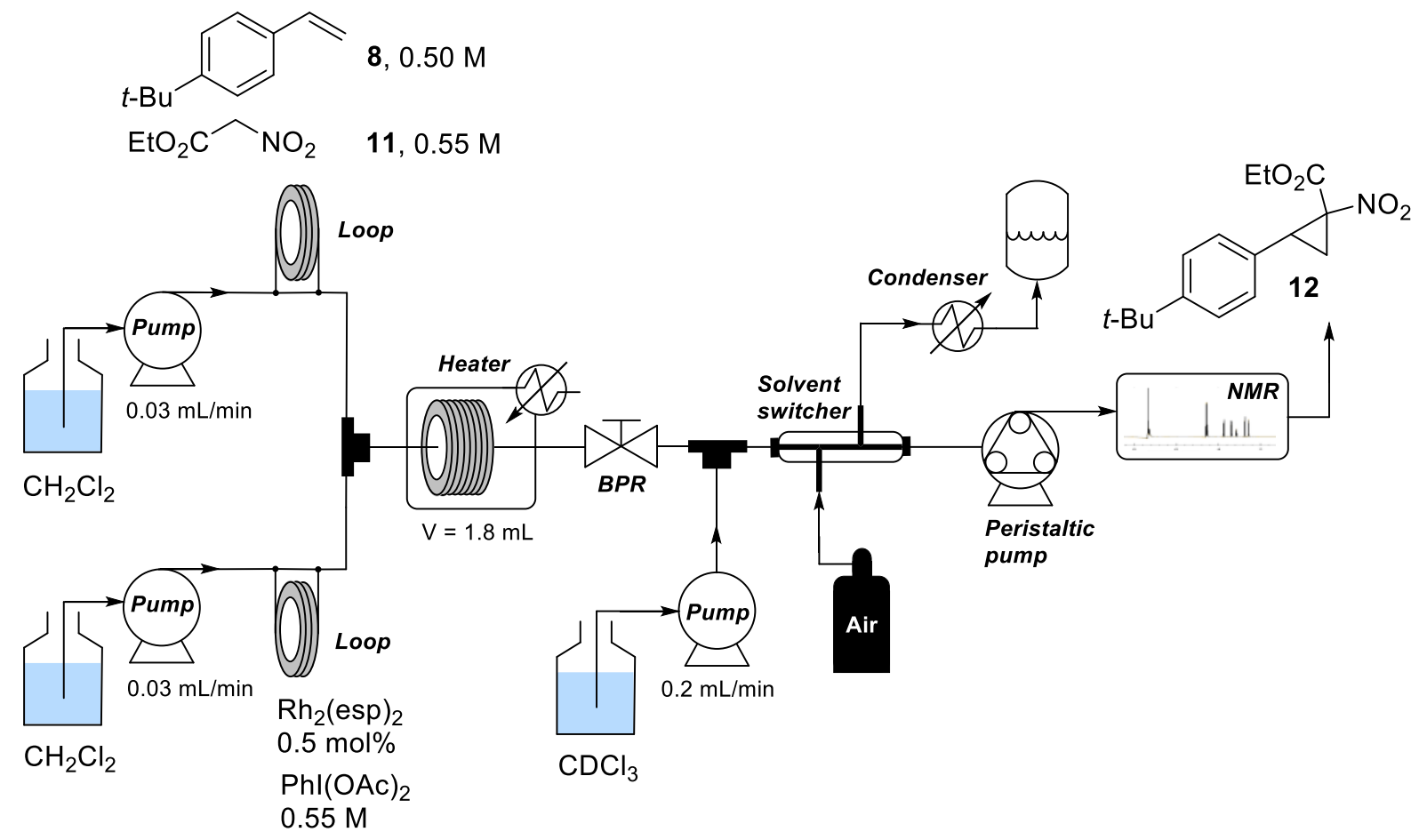

Fig. 8 Flow setup for the cyclopropanation of 4-tert-butylstyrene 8 with ethylnitroacetate $\mathbf{1 1 .}$ 
Examination of the COSY spectrum at the steady-state between $\delta_{\mathrm{H}}$ 0.5-5 ppm provided a number of useful insights (Figure 7). For instance, the formation of the cyclopropane ring of 12 was monitored through the correlation peaks $\mathrm{p} 5$ and $\mathrm{p} 5$ '. Another interesting feature of 2D NMR is the possibility to discriminate very similar electronic environments. For instance the ethoxy groups of the ester functions from 11 and 12 were clearly identified with the correlation peaks $\mathrm{p} 3$ and $\mathrm{p} 3$ ' for $\mathbf{1 1}$ and $\mathrm{p} 1$ and $\mathrm{p} 1$ ' for 12. An additional low field J-resolved 2D spectrum was recorded off-line to refine the interpretation of overlapped area.

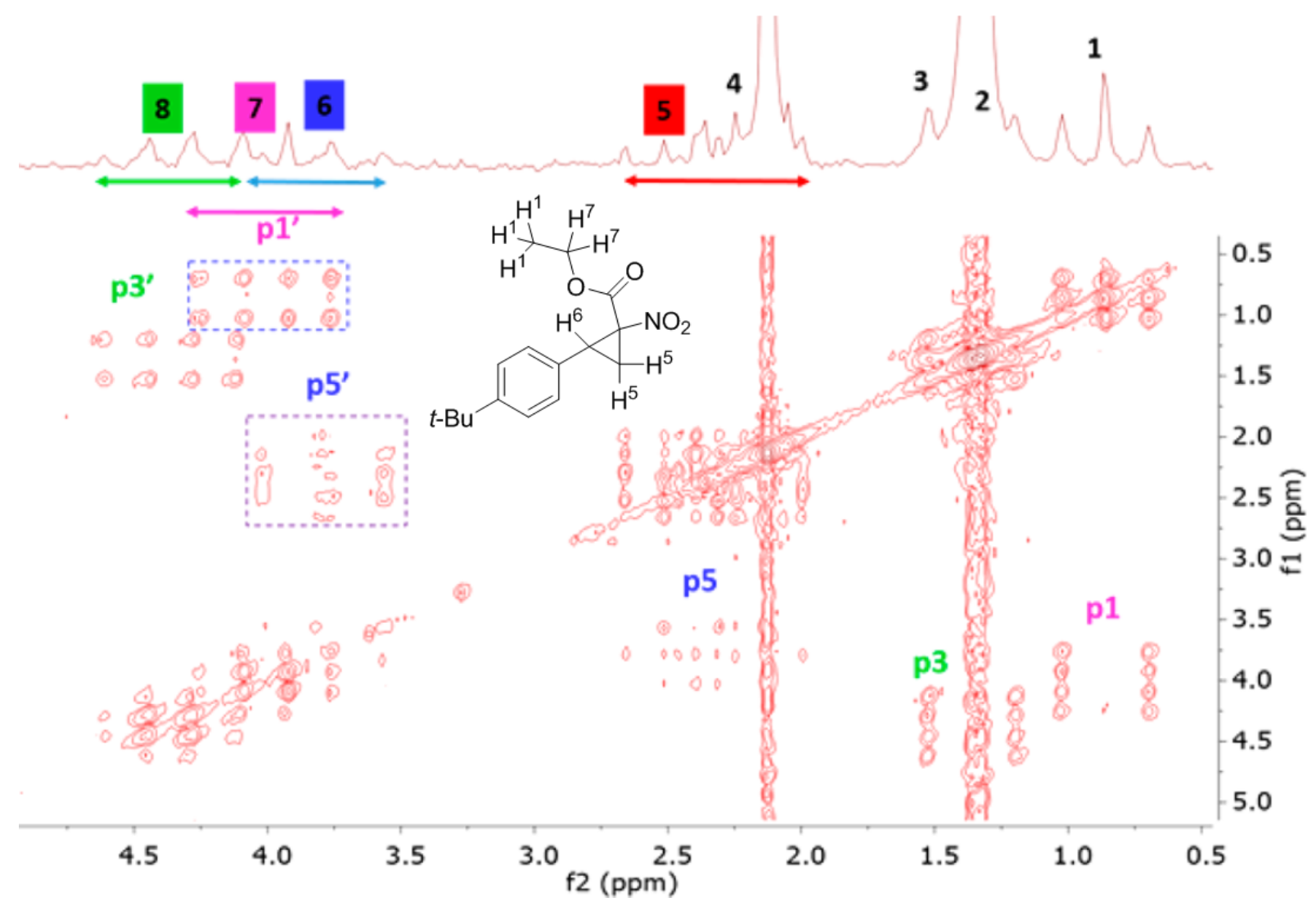

Fig. 9 COSY spectrum at the steady-state between $\delta_{H}$ 0.5-5 ppm. The NMR spectra were reproduced from ref. 66 with permission from The American Chemical Society. Cyclopropane 10 was included for clarity. Protons 2 refer to $t$-Bu of $\mathbf{6}$ and $\mathbf{1 0}$, protons 3 refer to $\mathrm{CH}_{3}$ of $\mathbf{6}$, protons 4 refer to $\mathrm{PhI}(\mathrm{OAc})_{2}$, protons 8 refer to $\mathrm{CH}_{2}$ of $\mathbf{6}$.

The in-line monitoring of chemical reactions is a powerful technology to assess in a quasireal-time kinetics and yields. NMR spectroscopy has a salient advantage compared to other analytical tools such as mass spectrometry, gas and liquid chromatography as it also allows deep structural investigations for the elucidation of selectivities. In this frame, the group of 
Cronin took advantage of in-line NMR monitoring for the simultaneous determination of yield and stereoselectivity in a Diels-Alder cycloaddition between cyclopentadiene $\mathbf{1 3}$ and acrolein 14 in THF providing endo and exo adducts 15. ${ }^{68}$ Three syringe pumps delivered cyclopentadiene 13 ( $2 \mathrm{M}$ in THF), acrolein 14 (2 M in THF) and $\mathrm{Sc}(\mathrm{OTf})_{3}(0.2 \mathrm{M}$ in THF), respectively, through a PTFE four-way mixer, to a coil reactor of $2.47 \mathrm{~mL}$ (Fig. 10). The inline benchtop NMR provided information on both the yield and the endo/exo selectivity through the examination of the aldehyde resonances between 9 and $9.5 \mathrm{ppm}$.

13, $0.4 \mathrm{M}$ in THF

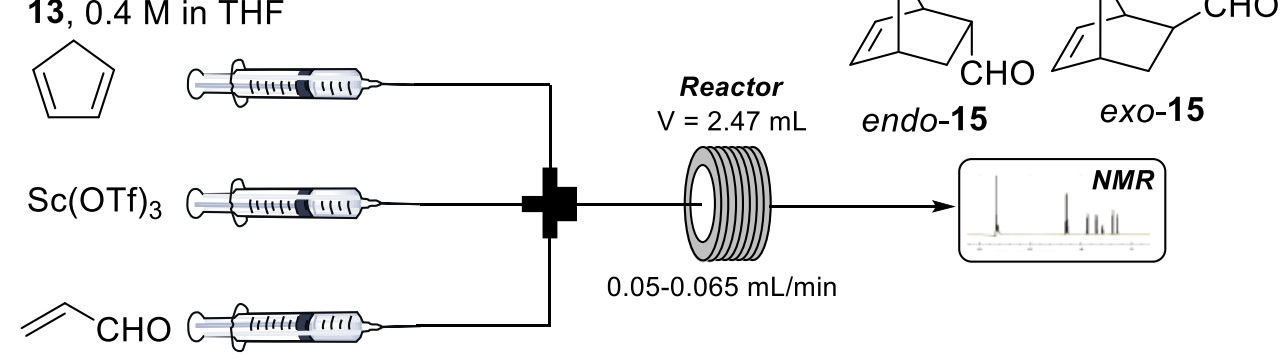

14, $0.4 \mathrm{M}$ in THF

Fig. 10 Flow setup for the cycloaddition of cyclopentadiene $\mathbf{1 3}$ with acrolein $\mathbf{1 5 .}$

Both objectives were studied as a function of the catalyst loading (Fig. 11). While the reaction yield substantially progressed upon increasing the catalyst loading, an opposite trend was observed for the endo/exo ratio which was eroded at high catalyst loading. Authors concluded from these observations that the endo adduct was the thermodynamic product while the exo was the kinetic.
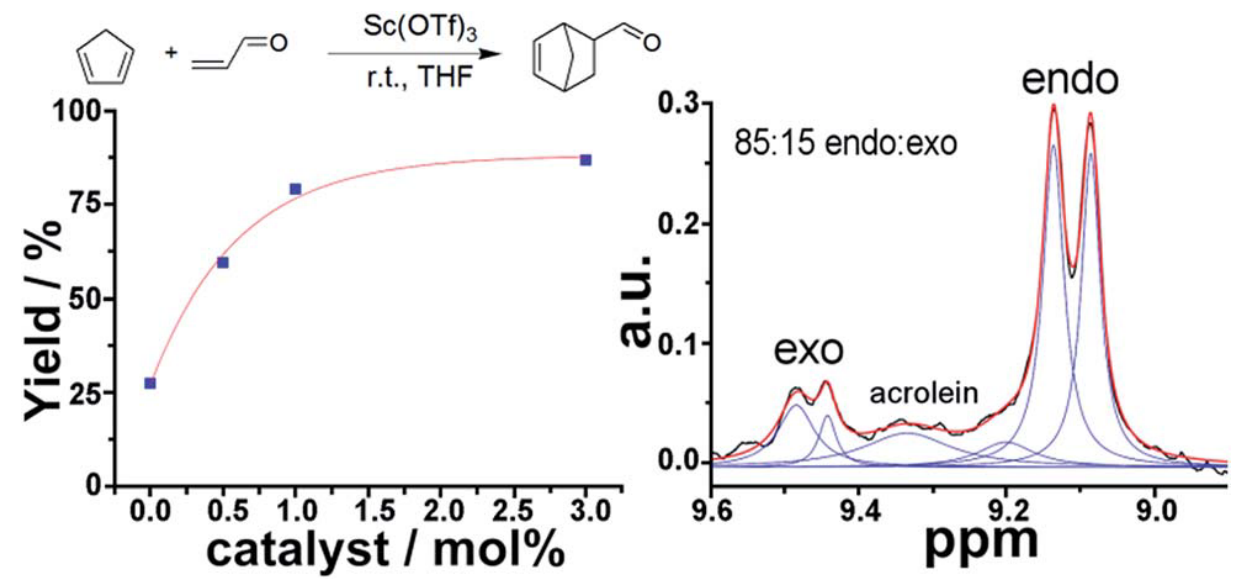

Fig. 11 Determination of the reaction yield as a function of the catalyst loading (left). Aldehyde resonances for cycloadduct 15 and acrolein 14. This figure was reproduced from ref. 68 - Published by The Royal Chemical Society. 


\section{Multiple in-line monitoring of continuous flow processes including benchtop NMR}

Information collected from in-situ reaction monitoring of continuous flow processes are furtive by nature and require a fast adaptation of the operator in charge of the data analysis. When the inline analytical tool provides the operator with ambiguous or unclear data, the continuous flow process has to be stopped to proceed with complementary off-line analyses for further understanding. Another and much more appealing approach consists in collecting diversified analytical data from two or more analytical tools connected in series to the flow reactor.

This strategy was studied by Farley and co-workers who reported on the use of both in-line FTIR and low-field NMR spectrometers, connected in a series at the outlet of the flow reactor, to follow the kinetic enzymatic resolution of racemic (cis)-2-methyloxan-4-ol 16 with vinyl butyrate 17 leading to (cis)-methylpyranylbutyrate 18, unreacted (cis)-2-methyloxan-4-ol 16 and acetaldehyde $\mathbf{1 9}$ (Fig. 12) ${ }^{69}$ In order to determine the viability of such a strategy to assess reliable reaction conversions of a benchmark transformation, authors compared the results obtained from the in-line FTIR and benchtop NMR tools and these data were further compared to off-line data obtained from high-field NMR and GC analyses. An operationally simple flow device was connected to a FTIR spectrometer equipped with a microflow cell, followed by a benchtop NMR apparatus working at $42.5 \mathrm{MHz}$ for the ${ }^{1} \mathrm{H}$ nucleus. A solution of (cis)-2methyloxan-4-ol $16(1 \mathrm{M})$ and vinyl butyrate $17(0.45 \mathrm{M})$ in anhydrous THF was pumped through packed Novozym ${ }^{\circledR} 435$ and the conversion of the kinetic resolution was recorded by the in-line analytical tools. As the volume of the flow cell of the benchtop NMR spectrometer was completely replaced every 15 seconds, a 90 degree pulse was implemented in the NMR sequence to increase the signal-to-noise ratio.

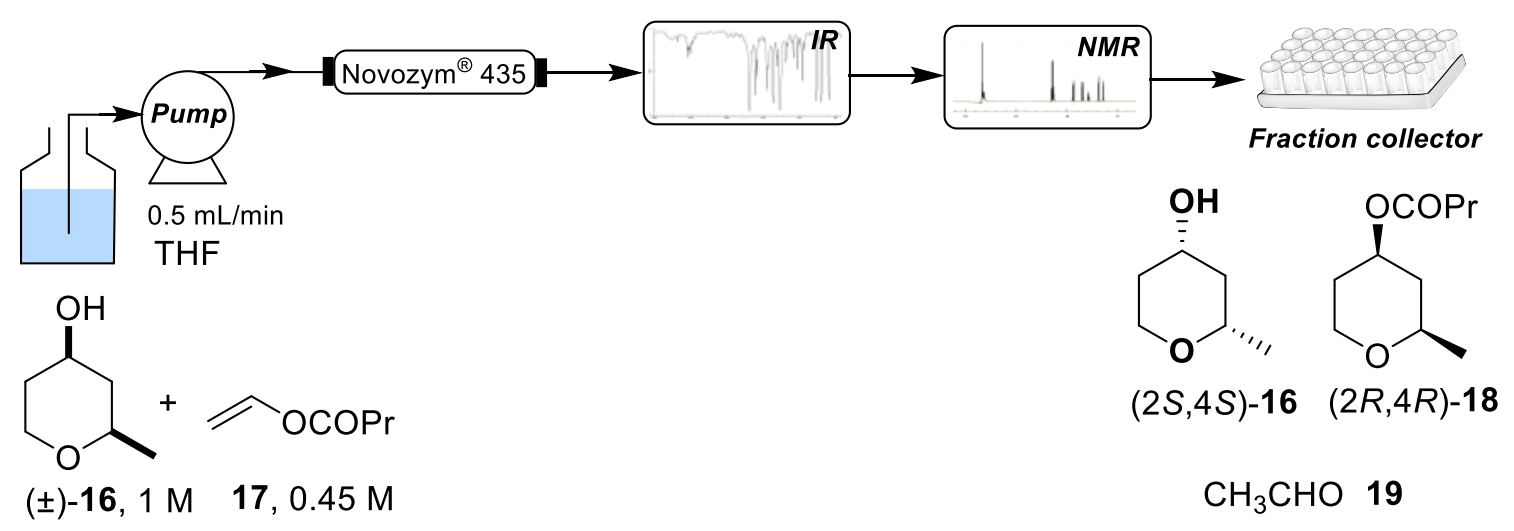


Fig. 12. Flow setup for the kinetic resolution of $( \pm)-16$ with Novozym $^{\circledR} 435$.

These studies revealed that single scan ${ }^{1} \mathrm{H}$ spectra, recorded every 15 seconds in nondeuterated THF, allowed to follow the progress of the reaction with flow rates ranging from 0.25 to $0.75 \mathrm{~mL} / \mathrm{min}$ through the progressive appearance of the methyl resonance of $(2 R, 4 R)$ 18 at $0.8 \mathrm{ppm}$ together with the disappearance of vinylic protons at 4.3 and $7.0 \mathrm{ppm}$ from vinyl butyrate 17. In turn, the FTIR spectroscopy monitored the formation of the ester bond in $(2 R, 4 R)-\mathbf{1 8}$ with the characteristic band at $1735 \mathrm{~cm}^{-1}$ and the disappearance of the vibration band $v(\mathrm{C}=\mathrm{C})$ at $1648 \mathrm{~cm}^{-1}$ from vinyl butyrate 17 . The conversion data compiled from the benchtop NMR and FTIR analyses allowed the determination of the optimum flow rate at 0.5 $\mathrm{mL} / \mathrm{min}$. Under optimal reaction conditions, the kinetic resolution of $27 \mathrm{~g}$ of racemic alcohol was carried out over a 24 hours period, leading to the desired ester 18 with an enantiomeric excess of $98.5 \%$.

The group of Ley also exploited the complementarity of FT-IR and low-field NMR spectroscopies for the valorization of $\mathrm{HCF}_{3}$ - a greenhouse gas produced from the polytetrafluoroethylene manufacture - into fluorinated compounds. ${ }^{70}$ To this end, the reactivity of the trifluoromethyl carbanion was studied in flow with electrophiles such as diarylketones, (hetero)aromatic aldehydes and chlorotriethylsilane 20. For instance, the trapping of the trifluoromethyl carbanion with chlorotriethylsilane $\mathbf{2 0}$ in a continuous flow mode provided trifluoromethyltriethylsilane 21 . The process was conducted with a three-stream flow reactor integrating in-line FT-IR and low field NMR analyses (Fig. 13). The first stream, managing the $\mathrm{HCF}_{3}$ solution $(0.72 \mathrm{M}$ in THF), consisted in a tube-in-tube device made from two concentric tube in which the inner tube is permeable to gas (Teflon AF-2400). ${ }^{71,72}$ The second line contained a solution of KHDMS in THF ( $1 \mathrm{M}$ in THF) while $\mathrm{Et}_{3} \mathrm{SiCl} 20$ (2 M in THF) was pumped in the third stream. The three streams met in a four-way valve and entered in a PTFE coil reactor $(14 \mathrm{~mL})$ cooled at $-40{ }^{\circ} \mathrm{C}$. The reactor outlet was connected with the in-line FT-IR device followed by the in-line benchtop NMR spectrometer. The line was pressurized at 75 psi with a back-pressure regulator to prevent out-gassing of $\mathrm{HCF}_{3}$ from the solvent mixture. The in-line monitoring allowed to both optimize the flow rate at $0.3 \mathrm{~mL} / \mathrm{min}$, corresponding to $c a$. $47 \mathrm{~min}$ of residence time, and fine-tune the stoichiometry of $\mathrm{Et}_{3} \mathrm{SiCl} \mathrm{20}$, used in excess $(2.7$ equiv.) to suppress the formation of $\mathrm{Et}_{3} \mathrm{SiF}$ as side-product (-151.02 ppm in the $\left.{ }^{19} \mathrm{~F} \mathrm{NMR}\right)$. The conversion was followed by IR spectroscopy through the disappearance of the band at $1132 \mathrm{~cm}^{-}$ ${ }^{1}\left(\mathrm{HCF}_{3}\right)$ together with the growth of the band at $1251 \mathrm{~cm}^{-1}\left(\mathrm{Et}_{3} \mathrm{SiCF}_{3} 20\right)$. Similarly, the consumption of $\mathrm{HCF}_{3}$ was monitored by ${ }^{19} \mathrm{~F}$ NMR with the disappearance of the doublet at - 
$79.49 \mathrm{ppm}\left(\mathrm{HCF}_{3}\right)$ together with the appearance of the singlet resonance at $-61.44 \mathrm{ppm}$ $\left(\mathrm{Et}_{3} \mathrm{SiCF}_{3} \mathbf{2 0}\right)$.

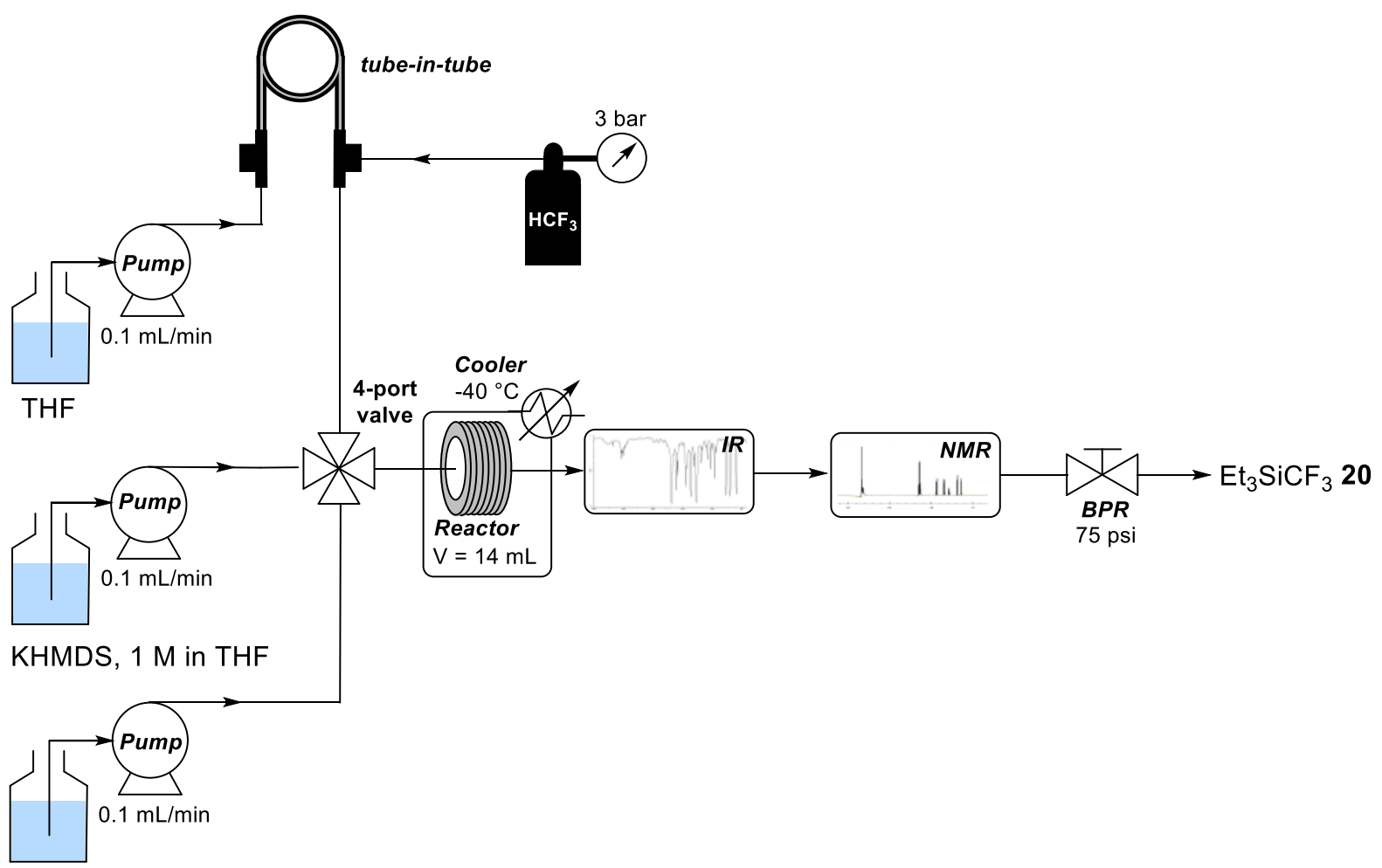

$\mathrm{Et}_{3} \mathrm{SiCl}, 2 \mathrm{M}$ in THF

Fig. 13. Flow setup for the trapping of the trifluoromethyl carbanion with chlorotriethylsilane 20.

Mass spectrometry is another analytical tool that can be used in association with benchtop NMR for quasi real-time monitoring of continuous flow processes. The group of Cronin reported the design of a flow device allowing the sequential synthesis of Schiff bases followed by their complexation with cationic $\mathrm{Cu}(\mathrm{I})$ salts. ${ }^{73}$ Both steps were monitored by in-line NMR and mass spectrometry (MS). In-line analytics were not placed in a series on the same flow device as it was preferred to use two different integrated flow devices with either a benchtop NMR spectrometer or a portable MS working in parallel. Therefore, each transformation was independently run two times in order to get structural information from both analytical tools. As an example, copper complex 21 was prepared with the three-stream flow device depicted in Fig. 14. The three stream delivered a solution of 2-pyridinecarboxaldehyde 22 in $\mathrm{CH}_{3} \mathrm{CN}(0.4$ $\mathrm{M})$, benzylamine 23 in $\mathrm{CH}_{3} \mathrm{CN}(0.4 \mathrm{M})$ and cationic $\mathrm{Cu}\left(\mathrm{CH}_{3} \mathrm{CN}\right)_{4} \mathrm{BF}_{4}$ in $\mathrm{CH}_{3} \mathrm{CN}(0.1 \mathrm{M})$, respectively. The two first sering pumps containing $\mathbf{2 2}$ and $\mathbf{2 3}$ worked at flow rates of (0.900 $\mathrm{mL} / \mathrm{min}$ ) and met in a 3-way connector. The Shiff base was formed in the reactor coil of 2.1 
$\mathrm{mL}$ with a residence time of about 1.2 minutes. Then, a third line containing $\mathrm{Cu}\left(\mathrm{CH}_{3} \mathrm{CN}\right)_{4} \mathrm{BF}_{4}$ was connected to the system via a 3-way connector and the resulting mixture entered with a total flow rate of $3.6 \mathrm{~mL} / \mathrm{min}$ in a second reactor coil of $0.7 \mathrm{~mL}$, corresponding to a residence time of $c a .12$ seconds only.

22, $0.4 \mathrm{M}$ in $\mathrm{CH}_{3} \mathrm{CN}$<smiles>NCc1ccccc1</smiles>
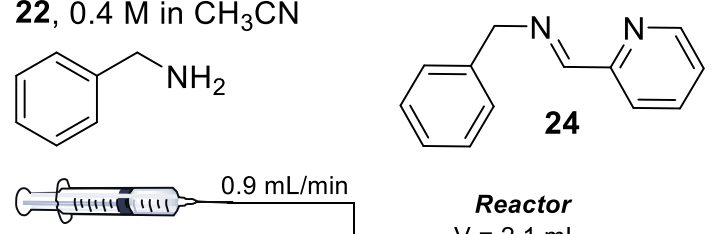

Syringe pumps

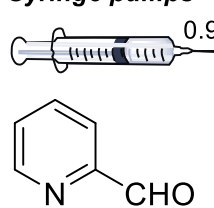

23, $0.4 \mathrm{M}$ in $\mathrm{CH}_{3} \mathrm{CN}$

\section{$\mathrm{Cu}\left(\mathrm{CH}_{3} \mathrm{CN}\right)_{4} \mathrm{BF}_{4}$ $0.1 \mathrm{M}$ in $\mathrm{CH}_{3} \mathrm{CN}$}

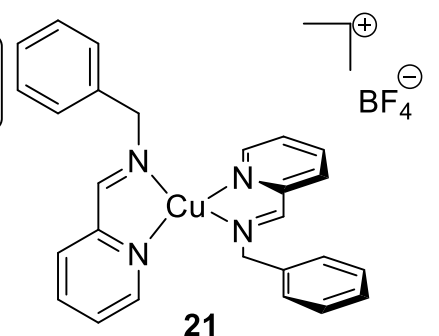

Fig. 14. Flow setup for the synthesis of copper complex 21.

The progress of the reaction was easily followed by ${ }^{1} \mathrm{H}$ NMR through the benchtop NMR spectrometer $(43 \mathrm{MHz})$ connected at the outlet of the second coil reactor (Fig. 15). The resonance of benzylic protons was closely monitored as the chemical shift shifted from $3.7 \mathrm{ppm}$ for benzylamine 22 to 4.82 ppm for ligand 24. Similarly, upon complexation with copper, resonnances from aromatic rings shifted at higher field from $c a$. $7.30 \mathrm{ppm}$ for ligand $\mathbf{2 4}$ to 7.09 ppm for complex 21. Similarly, the formation of complex 21 could also be observed by in-line MS analysis $(m / z=455.4)$. Interestingly, complex 21 , which was fully characterized through the in-line analytical tools, was found to be a transient intermediate evolving towards the dimeric structure 25 in the solid state upon oxidation in air and inclusion of a bridging carbonate moiety (Fig. 16). This result attests for the powerfulness of in-line analyses which allow to probe unstable intermediates that would be otherwise difficult or even impossible to detect through off-line analyses after a standard work up. 


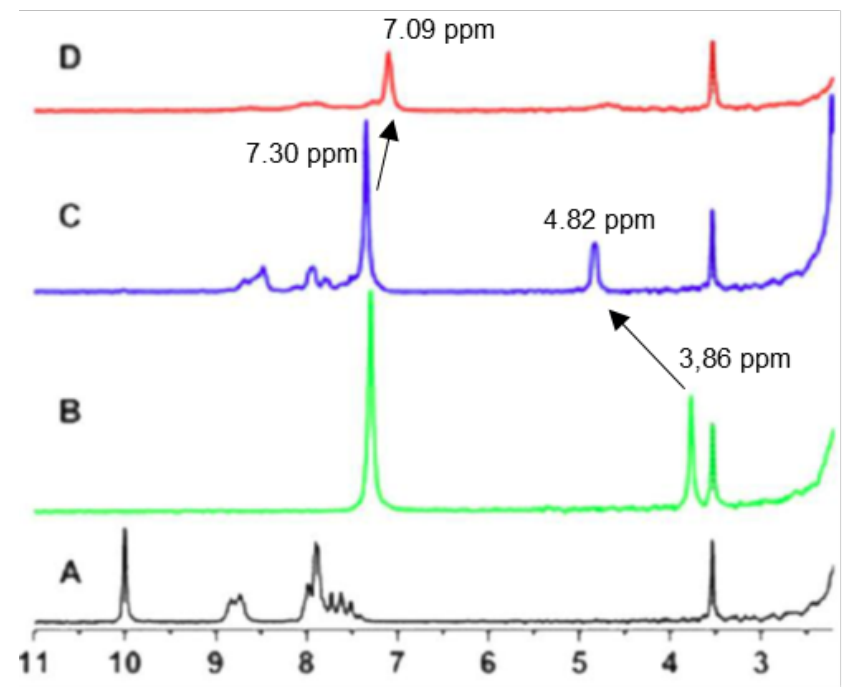

Fig. 15. Low-field NMR spectra of 2-pyridinecarboxaldehyde 23 (A), benzylamine 22 (B), ligand 24 (C) and complex 21 (D). The NMR spectra were reproduced from ref. 73 with permission from The Royal Chemical Society. Chemical shifts were added for clarity.

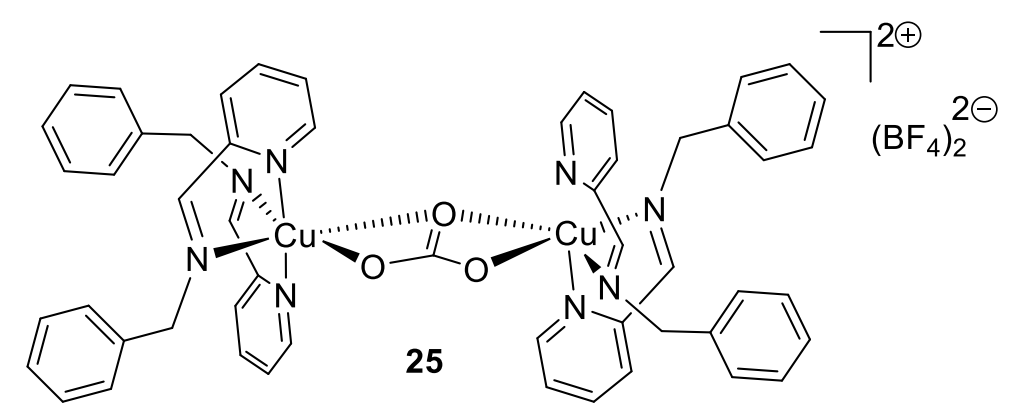

Fig. 16. Dimeric complex 25 formed upon oxidation of complex 21 in air.

The group of Ley also contributed to the use of in-line MS and NMR monitoring techniques with flow reactors. In this framework, they designed a flow reactor integrated with compact mass and benchtop NMR spectrometers for the Rh(II)-catalyzed cyclopropanation of styrene 8 with phenyl iodonium ylide $\mathbf{2 6}$ in $\mathrm{CH}_{2} \mathrm{Cl}_{2}$. The flow reactor was elaborated with a single stream delivering styrene $8(0.90 \mathrm{M})$ and $\mathrm{Rh}_{2}(\mathrm{esp})_{2}(0.1 \mathrm{~mol} \%)$ at $0.15 \mathrm{ml} / \mathrm{min}$ in a prepacked column of phenyl iodonium ylide 26 (Fig. 17). A 4-port valve connected to the reactor outlet, periodically sampled an aliquot of the flow stream to the compact mass spectrometer. The remaining flow stream was enriched with $\mathrm{CDCl}_{3}$ through the solvent switcher and then analyzed by ${ }^{1} \mathrm{H}$ NMR. The formation of cyclopropane 27 was monitored by ${ }^{1} \mathrm{H}$ NMR with the chemical shift of methoxy groups from ester functions at higher field. While they appeared as a singlet resonance at $3.5 \mathrm{ppm}$ in $\mathbf{2 6}$, dimethoxy moieties from $\mathbf{2 7}$ gave two singlets at 3.0 and $3.4 \mathrm{ppm}$. The monitoring by mass spectrometry appeared to be complementary as it proved that ylide $\mathbf{2 6}$ 
leached from the prepacked column and partially dimerized; this observation was not possible by ${ }^{1} \mathrm{H}$ NMR due to signal overlap.

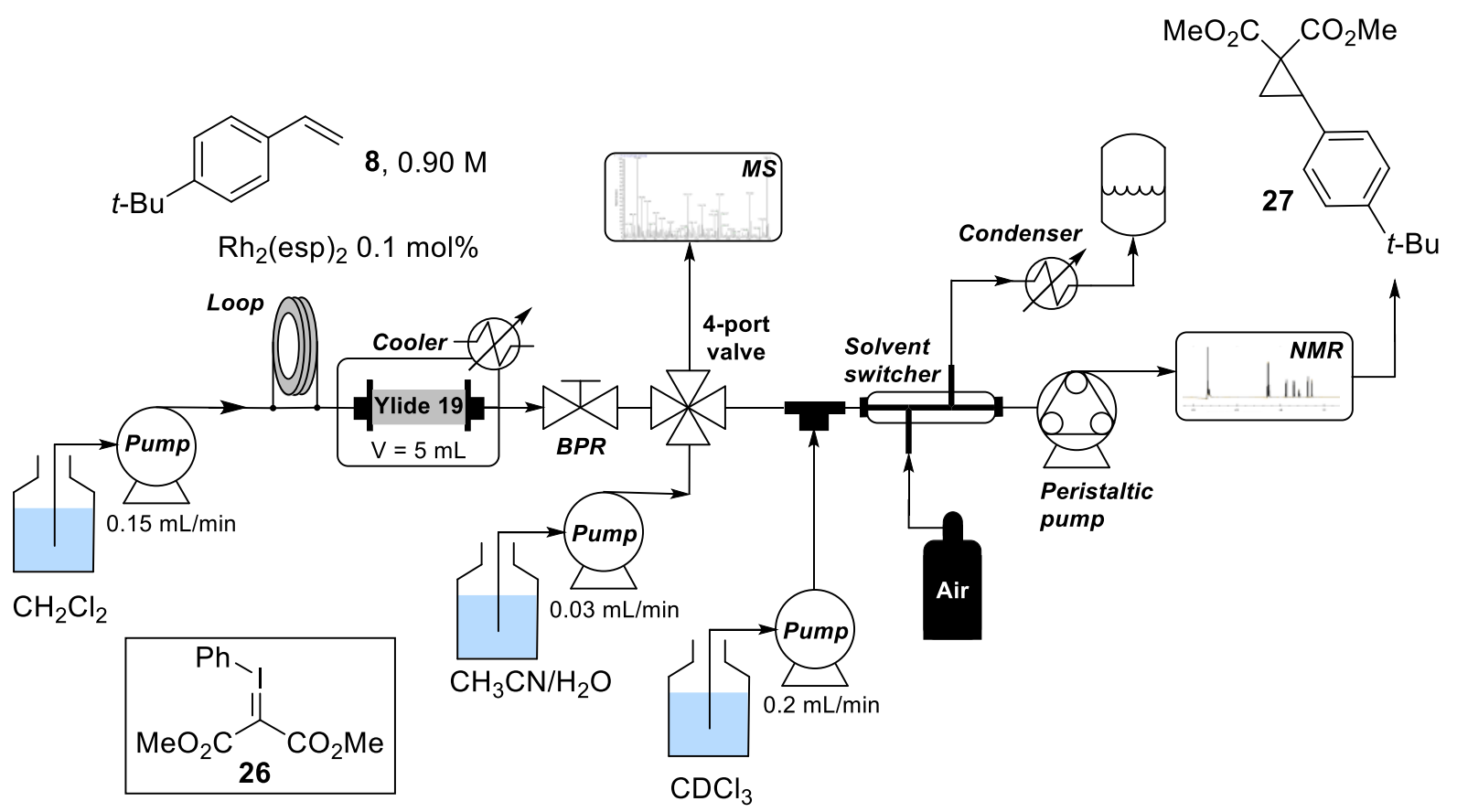

Fig. 17 Flow setup for the cyclopropanation of 4-tert-butylstyrene 8 with phenyl iodonium ylide 26.

\section{Self-optimizing flow reactor integrated with benchtop NMR}

In-line monitoring of chemical reaction in flow allows to adjust experimental parameters in real-time to either maximize or minimize an objective which can be the yield, productivity, cost... The development of self-optimizing flow reactors using optimization algorithms to update in real-time reaction parameters toward a desired objective is an emerging area of research ${ }^{74-78}$ pioneered by deMello and co-workers. ${ }^{79}$ Only a few research groups in the world harness this advanced technology at the frontier of chemical and computer science. While MS, ${ }^{31}$ FT-IR, ${ }^{30} \mathrm{LC}^{80-85}$ and $\mathrm{GC}^{86-89}$ are privileged in-line analytical tools for self-optimizing flow reactors, the group of Cronin demonstrated that benchtop NMR could be a powerful technology for the optimization of an imine synthesis from 4-fluorobenzaldehyde $\mathbf{2 8}$ and aniline 29, using trifluoroacetic as catalyst. ${ }^{68}$ The three-stream flow reactor allowed the formation of imine $\mathbf{3 0}$ in a $3.75 \mathrm{~mL}$ coil reactor (Fig. 18). The optimization was carried out with a modified version of the Nelder-Mead algorithm, using the residence time and reaction composition as the variables. The reaction yield was calculated by integration of the singlet resonance from the imine and 
aldehyde functions of $\mathbf{3 0}$ and $\mathbf{2 8}$, respectively. The fitness function optimized, which is related to the space-time yield, started from a randomly selected point, followed by successive iterations. After 29 experiments the algorithm stopped as it reached a stopping criteria and the $J$ value reached a maximum. Results extracted from the 29 iterations revealed a very noisy function suggesting that the algorithm used in this study was not well suited for such constrained optimization.<smiles>O=Cc1ccc(F)cc1</smiles>

28, $1 \mathrm{M}$ in $\mathrm{CH}_{3} \mathrm{CN}$

TFA

$0.05 \mathrm{M}$ in $\mathrm{CH}_{3} \mathrm{CN}$<smiles>Nc1ccccc1</smiles>

29, $2 \mathrm{M}$ in $\mathrm{CH}_{3} \mathrm{CN}$

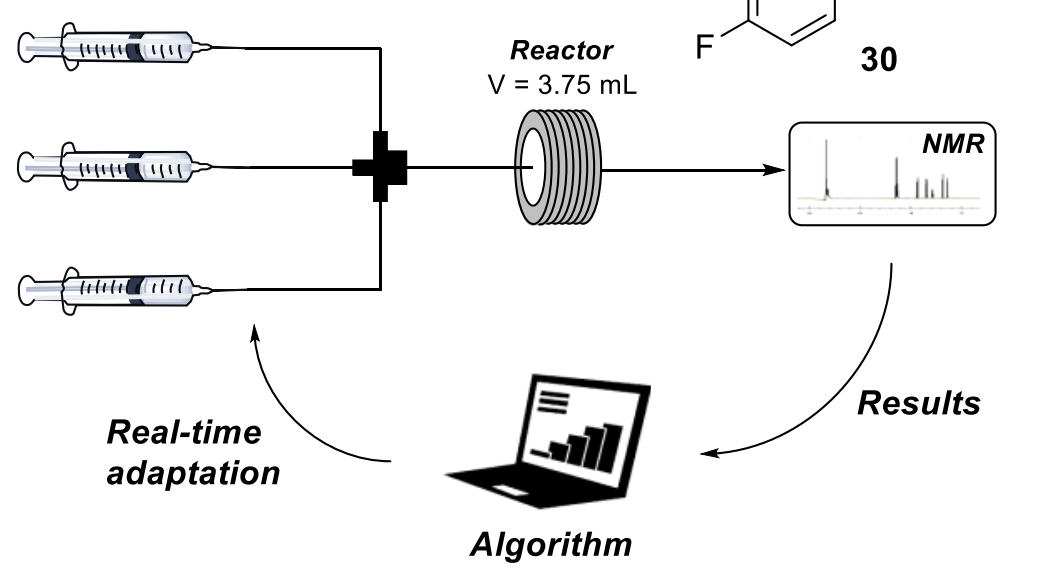

Fig. 18 Flow setup for the self-optimization of an imine condensation.

\section{Conclusion and outlook}

The integration of in-line analysis into continuous flow reactors allows the monitoring of chemical reactions on the fly without any specific handling and off-line work-up. Benchtop NMR spectrometers, which recently emerged on the market, are certainly amongst the most promising in-line analytical tools as they provide structural information and important insights to the on-going processes in a matter of seconds. Low-field benchtop NMR spectrometers feature a number of benefits for in-line monitoring in flow as they (i) can be placed under a fume hood, (ii) do not require cryogenic liquids and (iii) can be used with non-deuterated solvents. While most commercially available benchtop spectrometers can detect in routine ${ }^{1} \mathrm{H}$, ${ }^{19} \mathrm{~F},{ }^{13} \mathrm{C}$ and ${ }^{31} \mathrm{P}$ nuclei in one dimension, recent methodological developments allows the use of 2D-NMR methods and flow-compatible solvent-suppression pulse sequences. The perspectives of continuous flow chemistry is tremendous especially because of the numerous interplay with physic, engineering, computer science and mathematics. For instance, the monitoring of chemical reactions on the fly with Benchtop NMR spectrometers in association 
with feedback algorithms allow the control and adaptation of several parameters in real-time to modify the reaction outcome. Such autonomous machines will certainly become a standard technology in chemical laboratories for the next years to assist chemists on time-consuming and reiterative optimization steps.

Perspectives from the NMR side include the development of pulse sequences capable of simplifying further the NMR spectra of complex mixtures. These include, among others, the acquisition of ${ }^{13} \mathrm{C}$-decoupled ${ }^{1} \mathrm{H}$ NMR spectra to avoid overlap of the peaks of interest with potential solvent satellites (as discussed in section 3), the potential development of pure-shift methodologies capable of collapsing multiplets into singlets, ${ }^{90}$ or the implementation of diffusion-ordered spectroscopy to separate the sub-spectra of analytes in mixtures according to their molecular weight. ${ }^{91}$ These methods have not yet been implemented on a benchtop spectrometer, but hopefully this is just a question of time. Additional promising research prospects include the coupling with hyperpolarization approaches such as Dynamic Nuclear Polarization (DNP) $)^{92}$ or Para-Hydrogen Induced Polarization (PHIP) $)^{93}$ which have the potential to boost the sensitivity of NMR by several orders of magnitude. While the coupling of these approaches with flow chemistry is far from straightforward and will require major developments, a first encouraging step was taken by Blümich and co-workers who recently reported an approach for continuous hyperpolarization in flow by para-hydrogen..$^{94}$

\section{Conflicts of interest}

There are no conflicts to declare.

\section{Acknowledgements}

The authors gratefully acknowledge financial supports from the "Région des Pays de la Loire" (Paris scientifiques ResoNantes and SmartCat). PG and FXF are junior members of the "Institut Universitaire de France" (IUF). PG acknowledges members of the EBSI group, and particularly Dr. Boris Gouilleux, for insightful discussions.

\section{References}

1 M. B. Plutschack, B. Pieber, K. Gilmore and P. H. Seeberger, Chem. Rev., 2017, 117, 11796-11893. 
2 T. Noel and S. L. Buchwald, Chem. Soc. Rev., 2011, 40, 5010-5029.

3 A. Puglisi, M. Benaglia and V. Chiroli, Green Chem., 2013, 15, 1790-1813.

4 T. Tsubogo, T. Ishiwata and S. Kobayashi, Angew. Chem. Int. Ed., 2013, 52, 6590-6604.

5 L. Vaccaro, D. Lanari, A. Marrocchi and G. Strappaveccia, Green Chem., 2014, 16, 3680-3704.

6 R. Munirathinam, J. Huskens and W. Verboom, Adv. Synth. Catal., 2015, 357, 10931123.

7 J. Britton and C. L. Raston, Chem. Soc. Rev., 2017, 46, 1250-1271.

8 S. V. Ley, D. E. Fitzpatrick, R. J. Ingham and R. M. Myers, Angew. Chem. Int. Ed., 2015, 54, 3449-3464.

9 C. A. Shukla and A. A. Kulkarni, Beilstein J. Org. Chem., 2017, 13, 960-987.

10 J. Wegner, S. Ceylan and A. Kirschning, Chem. Commun., 2011, 47, 4583-4592.

11 S. V. Ley, Chem. Rec., 2012, 12, 378-390.

12 P. Plouffe, A. Macchi and D. M. Roberge, Org. Process Res. Dev., 2014, 18, 12861294.

13 N. Oger, E. Le Grognec and F.-X. Felpin, Org. Chem. Front., 2015, 2, 590-614.

14 B. Gutmann, D. Cantillo and C. O. Kappe, Angew. Chem. Int. Ed., 2015, 54, 6688-6728.

15 P. Poechlauer, J. Colberg, E. Fisher, M. Jansen, M. D. Johnson, S. G. Koenig, M. Lawler, T. Laporte, J. Manley, B. Martin and A. O’Kearney-McMullan, Org. Process Res. Dev., 2013, 17, 1472-1478.

16 G. Sipos, V. Gyollai, T. Sipőcz, G. Dormán, L. Kocsis, R. Jones and F. Darvas, J. Flow Chem., 2013, 3, 51-58.

17 M. Baumann and I. R. Baxendale, Beilstein J. Org. Chem., 2015, 11, 1194-1219.

18 R. Porta, M. Benaglia and A. Puglisi, Org. Process Res. Dev., 2016, 20, 2-25.

19 T. Razzaq, T. N. Glasnov and C. O. Kappe, Chem. Eng. Technol., 2009, 32, 1702-1716.

20 B. Gutmann, J.-P. Roduit, D. Roberge and C. O. Kappe, Angew. Chem. Int. Ed., 2010, 49, 7101-7105.

21 D. Cantillo and C. O. Kappe, J. Org. Chem., 2013, 78, 10567-10571.

22 P. J. Nieuwland, K. Koch, N. van Harskamp, R. Wehrens, J. C. M. van Hest and F. P. J. T. Rutjes, Chem. Asia. J., 2010, 5, 799-805.

23 T. Rodrigues, P. Schneider and G. Schneider, Angew. Chem. Int. Ed., 2014, 53, 57505758 .

24 M. Movsisyan, E. I. P. Delbeke, J. K. E. T. Berton, C. Battilocchio, S. V. Ley and C. V. Stevens, Chem. Soc. Rev., 2016, 45, 4892-4928. 
25 J. Yue, J. C. Schouten and T. A. Nijhuis, Ind. Eng. Chem. Res., 2012, 51, 14583-14609.

26 J. J. Haven and T. Junkers, Eur. J. Org. Chem., 2017, 2017, 6474-6482.

27 A. Echtermeyer, Y. Amar, J. Zakrzewski and A. Lapkin, Beilstein J. Org. Chem., 2017, 13, 150-163.

28 J. P. McMullen and K. F. Jensen, Org. Process Res. Dev., 2011, 15, 398-407.

29 B. J. Reizman and K. F. Jensen, Org. Process Res. Dev., 2012, 16, 1770-1782.

30 D. E. Fitzpatrick, C. Battilocchio and S. V. Ley, Org. Process Res. Dev., 2016, 20, 386394.

31 N. Holmes, G. R. Akien, R. J. D. Savage, C. Stanetty, I. R. Baxendale, A. J. Blacker, B. A. Taylor, R. L. Woodward, R. E. Meadows and R. A. Bourne, React. Chem. Eng., 2016, 1, 96-100.

32 D. L. Browne, S. Wright, B. J. Deadman, S. Dunnage, I. R. Baxendale, R. M. Turner and S. V. Ley, Rapid Commun. Mass Spectrom., 2012, 26, 1999-2010.

33 Y.-J. Hwang, C. W. Coley, M. Abolhasani, A. L. Marzinzik, G. Koch, C. Spanka, H. Lehmann and K. F. Jensen, Chem. Commun., 2017, 53, 6649-6652.

34 T. C. Malig, J. D. B. Koenig, H. Situ, N. K. Chehal, P. G. Hultin and J. E. Hein, React. Chem. Eng., 2017, 2, 309-314.

35 A. Perro, G. Lebourdon, S. Henry, S. Lecomte, L. Servant and S. Marre, React. Chem. Eng., 2016, 1, 577-594.

36 T. Brodmann, P. Koos, A. Metzger, P. Knochel and S. V. Ley, Org. Process Res. Dev., 2012, 16, 1102-1113.

37 C. F. Carter, H. Lange, S. V. Ley, I. R. Baxendale, B. Wittkamp, J. G. Goode and N. L. Gaunt, Org. Process Res. Dev., 2010, 14, 393-404.

38 Z. Qian, I. R. Baxendale and S. V. Ley, Chem. Eur. J., 2010, 16, 12342-12348.

39 T. L. LaPorte, M. Hamedi, J. S. DePue, L. F. Shen, D. Watson and D. Hsieh, Org. Process Res. Dev., 2008, 12, 956-966.

40 C. Luisa, J. D. A., Z. Xiaozhong, W. A. G. and S. J. V., Angew. Chem. Int. Ed., 2003, 42, 4669-4672.

41 N. Masamichi, U. Masafumi, S. Satoshi, A. K., U. Hiroshi, M. Okiko, N. Takeaki and T. Yutaka, Magn. Reson. Chem., 2007, 45, 989-992.

42 J. Bart, A. J. Kolkman, A. J. Oosthoek-de Vries, K. Koch, P. J. Nieuwland, H. Janssen, J. van Bentum, K. A. M. Ampt, F. P. J. T. Rutjes, S. S. Wijmenga, H. Gardeniers and A. P. M. Kentgens, J. Am. Chem. Soc., 2009, 131, 5014-5015. 
43 A. M. R. Hall, J. C. Chouler, A. Codina, P. T. Gierth, J. P. Lowe and U. Hintermair, Catal. Sci. Technol., 2016, 6, 8406-8417.

44 M. Maiwald, H. H. Fischer, Y.-K. Kim, K. Albert and H. Hasse, J. Magn. Reson., 2004, 166, 135-146.

45 D. A. Foley, E. Bez, A. Codina, K. L. Colson, M. Fey, R. Krull, D. Piroli, M. T. Zell and B. L. Marquez, Anal. Chem., 2014, 86, 12008-12013.

46 K. Hailu, G. Guthausen, W. Becker, A. König, A. Bendfeld and E. Geissler, Polym. Test., 2010, 29, 513-519.

47 L. Buljubasich, B. Blümich and S. Stapf, Chem. Eng. Sci., 2010, 65, 1394-1399.

48 S. K. Kuster, E. Danieli, B. Blumich and F. Casanova, Phys. Chem. Chem. Phys., 2011, 13, 13172-13176.

49 E. Danieli, J. Perlo, A. L. L. Duchateau, G. K. M. Verzijl, V. M. Litvinov, B. Blümich and F. Casanova, ChemPhysChem, 2014, 15, 3060-3066.

50 M. H. M. Killner, Y. Garro Linck, E. Danieli, J. J. R. Rohwedder and B. Blümich, Fuel, 2015, 139, 240-247.

51 S. D. Riegel and G. M. Leskowitz, TrAC, Trends Anal. Chem., 2016, 83, 27-38.

52 B. Gouilleux, B. Charrier, S. Akoka and P. Giraudeau, Magn. Reson. Chem., 2017, 55, 91-98.

53 L. Frydman, T. Scherf and A. Lupulescu, Proceedings of the National Academy of Sciences, 2002, 99, 15858-15862.

54 B. Gouilleux, L. Rouger and P. Giraudeau, eMagRes, 2016, 5, 913-922.

55 B. Gouilleux, L. Rouger and P. Giraudeau, in Annual Reports on NMR Spectroscopy, ed. G. A. Webb, Ed. Academic Press, 2018, vol. 98, pp. 75-144.

56 B. Gouilleux, B. Charrier, E. Danieli, J.-N. Dumez, S. Akoka, F.-X. Felpin, M. Rodriguez-Zubiri and P. Giraudeau, Analyst, 2015, 140, 7854-7858.

57 M. Goldbach, E. Danieli, J. Perlo, B. Kaptein, V. M. Litvinov, B. Blümich, F. Casanova and A. L. L. Duchateau, Tetrahedron Lett., 2016, 57, 122-125.

58 T. Tricotet and D. F. O'Shea, Chem. Eur. J., 2010, 16, 6678-6686.

59 P. R. D. Murray, D. L. Browne, J. C. Pastre, C. Butters, D. Guthrie and S. V. Ley, Org. Process Res. Dev., 2013, 17, 1192-1208.

60 Q. Deng, R. Shen, R. Ding and L. Zhang, Adv. Synth. Catal., 2014, 356, 2931-2936.

61 J. Wu, X. Yang, Z. He, X. Mao, T. A. Hatton and T. F. Jamison, Angew. Chem. Int. Ed., 2014, 53, 8416-8420. 
62 Q. Deng, R. Shen, Z. Zhao, M. Yan and L. Zhang, Chem. Eng. J., 2015, 262, 11681174.

63 B. Picard, B. Gouilleux, T. Lebleu, J. Maddaluno, I. Chataigner, M. Penhoat, F.-X. Felpin, P. Giraudeau and J. Legros, Angew. Chem. Int. Ed., 2017, 56, 7568-7572.

64 T. H. Rehm, C. Hofmann, D. Reinhard, H.-J. Kost, P. Lob, M. Besold, K. Welzel, J. Barten, A. Didenko, D. V. Sevenard, B. Lix, A. R. Hillson and S. D. Riegel, React. Chem. Eng., 2017.

65 B. J. Deadman, C. Battilocchio, E. Sliwinski and S. V. Ley, Green Chem., 2013, 15, 2050-2055.

66 B. Ahmed-Omer, E. Sliwinski, J. P. Cerroti and S. V. Ley, Org. Process Res. Dev., 2016, 20, 1603-1614.

67 B. Gouilleux, B. Charrier, S. Akoka, F.-X. Felpin, M. Rodriguez-Zubiri and P. Giraudeau, Trends Analyt. Chem., 2016, 83, 65-75.

68 V. Sans, L. Porwol, V. Dragone and L. Cronin, Chem. Sci., 2015, 6, 1258-1264.

69 K. A. Farley, U. Reilly, D. P. Anderson, B. P. Boscoe, M. W. Bundesmann, D. A. Foley, M. S. Lall, C. Li, M. R. Reese and J. Yan, Magn. Reson. Chem., 2017, 55, 348-354.

70 B. Musio, E. Gala and S. V. Ley, ACS Sustainable Chem. Eng., 2018, 6, 1489-1495.

71 A. Polyzos, M. O'Brien, T. P. Petersen, I. R. Baxendale and S. V. Ley, Angew. Chem. Int. Ed., 2011, 50, 1190-1193.

72 M. Brzozowski, M. O’Brien, S. V. Ley and A. Polyzos, Acc. Chem. Res., 2015, 48, 349362.

73 L. Porwol, A. Henson, P. J. Kitson, D.-L. Long and L. Cronin, Inorg. Chem. Front., 2016, 3, 919-923.

74 M. Rasheed and T. Wirth, Angew. Chem. Int. Ed., 2011, 50, 357-358.

75 D. C. Fabry, E. Sugiono and M. Rueping, Isr. J. Chem., 2014, 54, 341-350.

76 D. C. Fabry, E. Sugiono and M. Rueping, React. Chem. Eng., 2016, 1, 129-133.

77 V. Sans and L. Cronin, Chem. Soc. Rev., 2016, 45, 2032-2043.

78 B. J. Reizman and K. F. Jensen, Acc. Chem. Res., 2016, 49, 1786-1796.

79 S. Krishnadasan, R. J. C. Brown, A. J. deMello and J. C. deMello, Lab Chip, 2007, 7, 1434-1441.

80 J. P. McMullen and K. F. Jensen, Org. Process Res. Dev., 2010, 14, 1169-1176.

81 J. P. McMullen, M. T. Stone, S. L. Buchwald and K. F. Jensen, Angew. Chem. Int. Ed., 2010, 49, 7076-7080.

82 B. J. Reizman and K. F. Jensen, Chem. Commun., 2015, 51, 13290-13293. 
83 B. J. Reizman, Y.-M. Wang, S. L. Buchwald and K. F. Jensen, React. Chem. Eng., 2016, 1, 658-666.

84 N. Holmes, G. R. Akien, A. J. Blacker, R. L. Woodward, R. E. Meadows and R. A. Bourne, React. Chem. Eng., 2016, 1, 366-371.

85 B. E. Walker, J. H. Bannock, A. M. Nightingale and J. C. deMello, React. Chem. Eng., 2017, 2, 785-798.

86 R. A. Bourne, R. A. Skilton, A. J. Parrott, D. J. Irvine and M. Poliakoff, Org. Process Res. Dev., 2011, 15, 932-938.

87 A. J. Parrott, R. A. Bourne, G. R. Akien, D. J. Irvine and M. Poliakoff, Angew. Chem. Int. Ed., 2011, 50, 3788-3792.

88 D. N. Jumbam, R. A. Skilton, A. J. Parrott, R. A. Bourne and M. Poliakoff, J. Flow Chem., 2012, 2, 24-27.

89 Z. Amara, E. S. Streng, R. A. Skilton, J. Jin, M. W. George and M. Poliakoff, Eur. J. Org. Chem., 2015, 6141-6145.

90 K. Zangger, Prog. Nucl. Magn. Reson. Spectrosc., 2015, 86-87, 1-20.

91 G. A. Morris, in eMagRes, John Wiley \& Sons, Ltd, 2007.

92 B. Plainchont, P. Berruyer, J.-N. Dumez, S. Jannin and P. Giraudeau, Anal. Chem., 2018, 90, 3639-3650.

93 S. B. Duckett and R. E. Mewis, in Hyperpolarization Methods in NMR Spectroscopy, ed. L. T. Kuhn, Springer Berlin Heidelberg, Berlin, Heidelberg, 2013, pp. 75-103.

94 S. Lehmkuhl, M. Wiese, L. Schubert, M. Held, M. Küppers, M. Wessling and B. Blümich, J. Magn. Reson., 2018, 291, 8-13. 